\title{
Advances and Obstacles in Homology-Mediated Gene Editing of Hematopoietic Stem Cells
}

\author{
Christi T. Salisbury-Ruf and Andre Larochelle *(D) \\ Cellular and Molecular Therapeutics Branch, National Heart, Lung and Blood Institute (NHLBI), \\ National Institutes of Health (NIH), Bethesda, MD 20892, USA; christi.gurniak@nih.gov \\ * Correspondence: larochea@nhlbi.nih.gov
}

\section{check for}

updates

Citation: Salisbury-Ruf, C.T.; Larochelle, A. Advances and Obstacles in Homology-Mediated Gene Editing of Hematopoietic Stem Cells. J. Clin. Med. 2021, 10, 513. https://doi.org/10.3390/jcm10030513

Academic Editor: Marina Cavazzana Received: 12 December 2020

Accepted: 26 January 2021

Published: 1 February 2021

Publisher's Note: MDPI stays neutral with regard to jurisdictional claims in published maps and institutional affiliations.

Copyright: (c) 2021 by the authors. Licensee MDPI, Basel, Switzerland. This article is an open access article distributed under the terms and conditions of the Creative Commons Attribution (CC BY) license (https:// creativecommons.org/licenses/by/ $4.0 /)$.
Abstract: Homology-directed gene editing of hematopoietic stem and progenitor cells (HSPCs) is a promising strategy for the treatment of inherited blood disorders, obviating many of the limitations associated with viral vector-mediated gene therapies. The use of CRISPR/Cas9 or other programmable nucleases and improved methods of homology template delivery have enabled precise ex vivo gene editing. These transformative advances have also highlighted technical challenges to achieve high-efficiency gene editing in HSPCs for therapeutic applications. In this review, we discuss recent pre-clinical investigations utilizing homology-mediated gene editing in HSPCs and highlight various strategies to improve editing efficiency in these cells.

Keywords: gene editing; hematopoietic stem and progenitor cells; homology-directed repair; CRISPR-Cas9; AAV6

\section{Introduction}

The modification or insertion of genes was initially proposed in the early 1970s as a curative approach for inherited disorders [1]. Hematopoietic stem cells (HSCs) are preferred targets for genetic therapies owing to their ability to sustain lifelong hematopoiesis, affording the possibility of durably alleviating a range of conditions. Current gene therapy approaches for inherited blood disorders primarily entail the harvest of hematopoietic stem and progenitor cells (HSPCs) from individuals with an underlying genetic defect and their adoptive transfer after genetic modification ex vivo (Figure 1a). Decades of allogeneic HSPC transplantation performed in the clinic provided a roadmap for therapeutic translation of this novel approach. The avoidance of allo-reactive complications and the reduced complexity of conditioning regimens in autologous transplantation of genetically modified HSPCs provide substantial advantages over allogeneic HSPC transplantation options for these disorders.

Clinical trials using gene delivery vectors based on $\gamma$-retroviral vectors were initially approved in the 1990s, but only low numbers of corrected cells were detected, and phenotypic correction of the underlying defect was not observed. A refocus on optimizing ex vivo transduction conditions and addition of conditioning regimens to favor engraftment of transduced cells led to the first unequivocal clinical successes in patients with primary immunodeficiencies [2-4]. However, the subsequent reporting of malignancies caused by vector-mediated insertional activation of proto-oncogenes in treated patients [5-7] encouraged the development of alternative vector designs primarily based on retroviruses of the HIV-1 Lentivirinae subfamily (Figure 1b). Unique constituents of lentiviral vectors facilitate their nuclear translocation within non-dividing HSPCs, further enhancing transduction of these cells. The elimination of portions of the $3^{\prime}$-LTR promoter and enhancer elements in these vectors also provide a key self-inactivating (SIN) safety feature to alleviate concerns on possible recombination with endogenous HIV particles or unintended activation of proto-oncogenes near the genomic site of vector integration. For these SIN vectors, however, the efficiency of transgene expression is highly dependent on the addition of 
an internal ubiquitous promoter, and reduced or ectopic expression of the therapeutic gene can be limiting in disorders requiring robust or targeted transgene expression for a therapeutic effect.

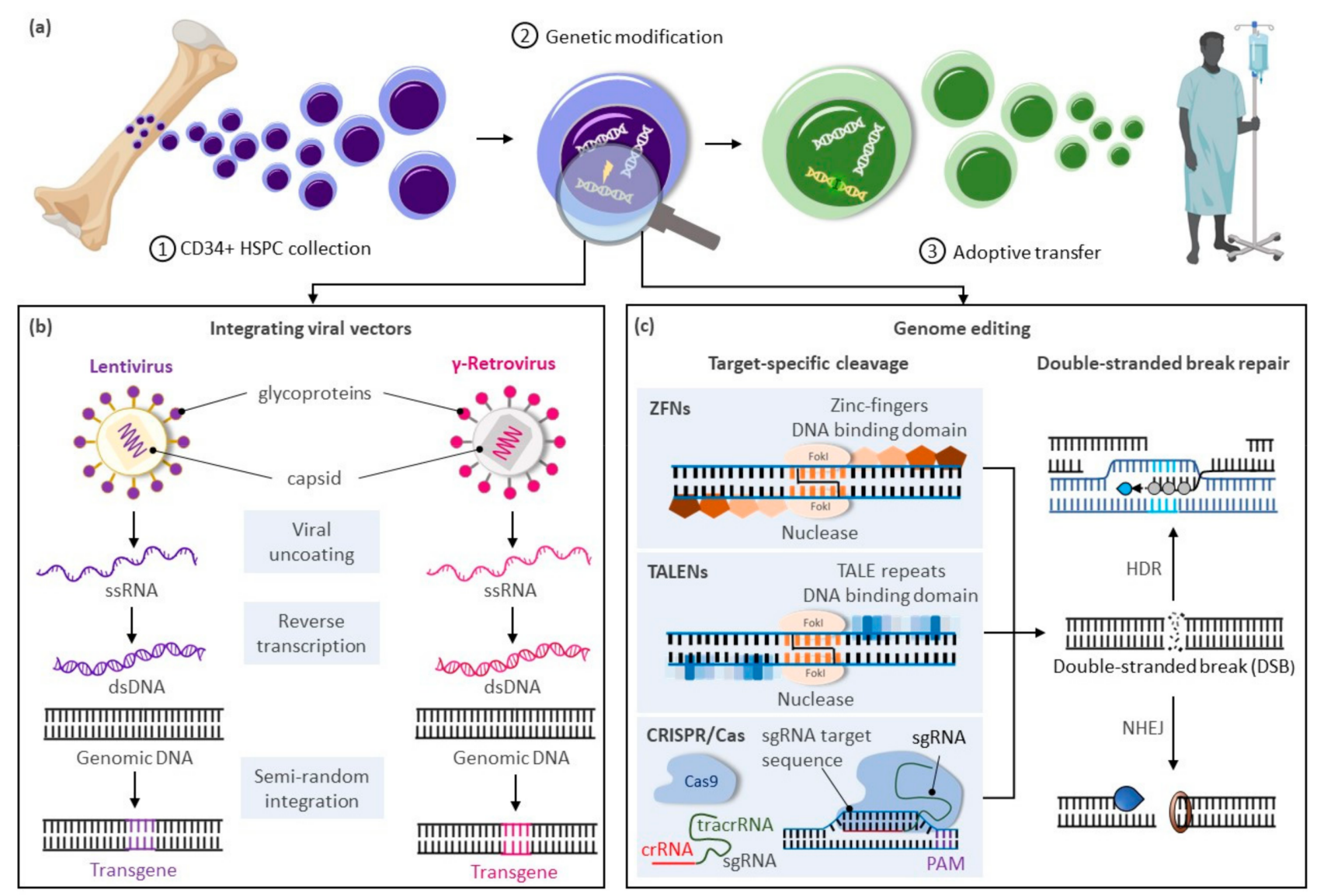

Figure 1. Gene therapy approaches for inherited blood disorders. (a) General scheme for gene therapies of inherited blood disorders: (1) Isolation of CD34+ hematopoietic stem and progenitor cells (HSPCs) from bone marrow harvests or mobilized peripheral blood cell collections; (2) Ex vivo genetic modification of HSPCs; (3) Adoptive transfer of genetically corrected cells to the patient generally following a reduced intensity conditioning regimen to enhance engraftment of the treated cells. (b) Largely random pattern of transgene integration within the target cellular genome after genetic modification of HSPCs using integrating viral vectors based on lentiviruses or gamma-retroviruses. (c) Precise integration of therapeutic genes using genome editing approaches based on zinc-finger nucleases (ZFNs), transcription activator-like effector (TALE) nucleases (TALENS), or the clustered regularly interspaced palindrome repeat (CRISPR)-associated (Cas) platform. Abbreviations: crRNA, CRISPR RNA; dsDNA, double-stranded DNA; DSBs, double-stranded breaks; HDR, homology directed repair; NHEJ, non-homologous end-joining; PAM, protospacer-adjacent motif; sgRNA, single guide RNA; ssRNA, single-stranded RNA; tracrRNA, trans-activating CRISPR RNA.

In recent years, transformative advances have emerged to precisely edit cellular genomes (Figure 1c). Unlike integrating vectors, which can only facilitate gene addition within undefined loci of the cellular genome, novel editing strategies can mediate precise gene correction, gene ablation, and targeted gene addition within cells. Hence, these technologies further address safety concerns associated with integrating vectors, allow more robust and physiologic gene expression by targeted integration of transgenes near endogenous promoters, and extend gene therapies to dominant negative disorders requiring replacement of abnormal gene products rather than simple gene addition. Building on three decades of scientific advances and clinical successes using integrating viral vectors, targeted gene editing in HSPCs is now undergoing similar accelerated pre-clinical and clinical development. In this review, we summarize the current state of targeted gene delivery 
in HSPCs and examine new strategies developed to improve gene editing efficiency to levels necessary for effective treatment of inherited blood disorders.

\section{The Process of Genome Editing}

High-efficiency targeted genome editing in mammalian cells generally depends on the initial introduction of a DNA double-stranded break (DSB) at the chosen genomic locus to stimulate cellular DNA repair to yield desired outcomes. As summarized in this section, various cellular nucleases have been engineered to recognize individual target sequences and induce the necessary DSBs and DNA repair response for targeted DNA modification (Figure 1c). Alternative strategies to manipulate cellular genomes that do not rely on double-stranded DNA cleavage, including base editors [8-11], prime editors [12], and transposases/recombinases [13-16], were also developed in recent years and have been reviewed elsewhere [17].

\subsection{Targeted DNA Double-Stranded Breaks with Engineered DNA Ucleases}

Programmable DNA nucleases emerged in the late 1990s and early genome editing studies relied on protein guided synthetic zinc-finger nucleases (ZFNs) (Figure 1c) [18]. ZFNs consist of a non-specific FokI nuclease domain and a finger domain that provides DNA binding specificity. Each amino acid within the finger domain recognizes three DNA base pairs (bp), with several domains required to recognize a 9-18 bp motif. Specific DSBs are made upon dimerization of ZFNs at their FokI domains on opposite strands of the DNA. Zinc-finger nucleases were first shown to successfully edit drosophila DNA in 2002 [19] and subsequently in primary human T-cells in 2005 [20]. ZFNs have now entered clinical trials [21,22], but their widespread use has been hindered by constraints of the DNA-triplet recognition motif and the specialized expertise required to customize the DNA binding nuclease effector proteins for each genomic target site.

A more versatile transcription activator-like effector (TALE) DNA binding domain from the Xanthomonas spp. proteobacteria [23] was subsequently tethered to the same Fok1 endonuclease domain found in ZFNs to create TALE nucleases (TALENs) (Figure 1c) [24]. TALE domains are modular arrays of conserved repeats of 33-35 amino acids in length. Each repeat binds to a single nucleotide within the target sequence with a binding specificity dictated by the repeat-variable di-residue (RVD) at amino acid positions 12 and 13 of the TALE domain [25]. TALENs have been successfully used in pre-clinical models to edit HSPCs at the CCR5 locus for treatment of HIV [26] and correct the sickle cell mutation in HBB with a single-stranded oligonucleotide (ssODN) donor template [27]. While TALENs' RVD-DNA recognition code facilitates the design of binding domains with a broader targeting range than ZFNs, TALEN-based gene editing technologies still entail the complex assembly of nucleases specific to each targeted DNA locus.

The bacterial clustered regularly interspaced palindrome repeat (CRISPR) and the CRISPR-associated (Cas) protein, known as CRISPR/Cas, constitutes a novel class of RNA-guided programmable nucleases with unique simplicity and flexibility for targeted gene therapies (Figure 1c) [28]. Identified as a bacterial adaptive immune system [29], CRISPR destroys foreign DNA using the Cas endonuclease in a sequence-specific manner. These naturally occurring immune systems have been categorized as either CRISPR-Cas class 1 , which requires complexes composed of several effector proteins for cleavage, or class 2 , which allows cleavage of nucleic acids with a single effector domain. Due to their simpler requirements, systems based on class 2 have been favored for genome editing. Class 2 is further partitioned into types II (Cas 9), V (Cas 12), and VI (Cas 13). The type II CRISPR/Cas9 system derived from Streptococcus pyogenes (SpCas9) is currently the most widely used tool for genome editing in hematopoietic and other cellular sources. Cas9 is guided by a dual-RNA complex consisting of a universal trans-activating CRISPR RNA (tracrRNA) that recruits the Cas9 protein, and a CRISPR RNA (crRNA) with homology to a specific DNA sequence. The system was simplified for genome editing applications by synthetic fusion of both RNAs into a single guide RNA (gRNA). Small chemical groups 
may also be introduced at the extremities of synthesized gRNA to enhance gene editing, as shown at three therapeutically relevant loci in human HSPCs [30]. The Cas9/gRNA ribonucleoprotein (RNP) complex binds to a cognate proto-spacer adjacent motif (PAM) sequence (i.e., NGG) at the target locus, facilitating heteroduplex formation between the guide RNA sequence and the unwound target DNA strand. Cas9 then undergoes conformational changes, which activate its constituent $\mathrm{HNH}$ and RuvC nuclease domains to promote cleavage of both target (i.e., bound to the gRNA) and non-target DNA strands, respectively. The process results in formation of predominantly blunt-ended DSBs upstream of the PAM sequence at the chosen locus.

Several Cas9 variants or alternative Cas proteins have been developed to offset limitations of the CRISPR editing system based on SpCas9. For instance, off-target gene editing at unintended sites may result in deleterious cellular effects. Dual-strand targeting using paired Cas9 nickases derived by mutating the RuvC (Cas $\left.9^{\mathrm{D} 10 \mathrm{~A}}\right)$ or $\mathrm{HNH}(\mathrm{H} 840 \mathrm{~A})$ catalytic domains, and two adjacent gRNAs targeting opposing strands of a DNA target [28], can enhance CRIPR/Cas9 accuracy. Similarly, systems based on catalytically inactive Cas 9 fused to Fok1 (fCas9), which require recruitment of two Fok1 domains for cleavage [31], can lower the probability of off-target editing. However, design of these systems is more complex, and efficiency is generally lower. Reduced off-target activity was also reported using Cas9 isolated from the alternative bacterial species Streptococcus thermophilus [32] and Francisella novicida (FnCas9) [33], and from type V CRISPR effector Cas12b derived from Bacillus hisashii (BhCas12b) [34]. In HSPCs, the high-fidelity (HiFi) Cas9 mutant improved the on-to-off target ratio when delivered as a purified protein [35], but the potential benefits of other engineered Cas 9 variants remain to be determined, as they generally support lower on-target activity [27]. The large cargo size of the CRISPR/SpCas9 system represents another limitation of this technology, precluding packaging within some viral delivery vectors for gene therapy applications. More compact wild-type [36] and mutant [37] Cas9 nucleases from Staphylococcus aureus (SaCas9), Cas9 orthologs derived from Campylobacter jejuni (CjCas9) [38] and Neisseria meningitidis (NmCas9) [39], and type V Cas12e notable for its small size [40] were recently characterized to address this shortcoming. Another disadvantage of the CRISPR/SpCas9 system is the inherent NGG-PAM recognition requirement that limits Cas target site ranges. Several variants have been reported to expand the genome editing armamentarium, such as type V Cas12a nuclease that generally uses orthogonal T-rich PAM sequences [41], NmCas9 that recognizes pyrimidine-rich PAM sequences [39,42], a near PAM-less "SpRY" variant of the prototypical SpCas9 [43] and numerous other Cas effectors with altered PAM specificity $[44,45]$.

\subsection{Cellular Pathways for Repair of DNA Double-Stranded Breaks}

In mammalian cells, DNA DSBs are repaired by classic non-homologous end joining (C-NHEJ), alternative NHEJ (alt-NHEJ, also known as microhomology-mediated end joining, MMEJ), single-strand annealing (SSA), and homology-directed repair (HDR) (Figure 2). The choice of DNA repair pathway after nuclease-mediated DSB formation is influenced by several factors that primarily coalesce on the key role that cell cycle plays in regulating DSB repair [46]. For instance, various phases of the cell cycle will differ in abundance or availability of pathway-specific DNA repair proteins and homologous DNA templates, and the repair mechanism favored may be influenced by the chromatin state of the target cells [47]. In genome editing applications, the DNA end structures induced by distinct programmable nucleases (i.e., blunt ends, $3^{\prime}$ overhangs, or $5^{\prime}$ overhangs) may also trigger distinct cellular pathways for repair of DSBs. 


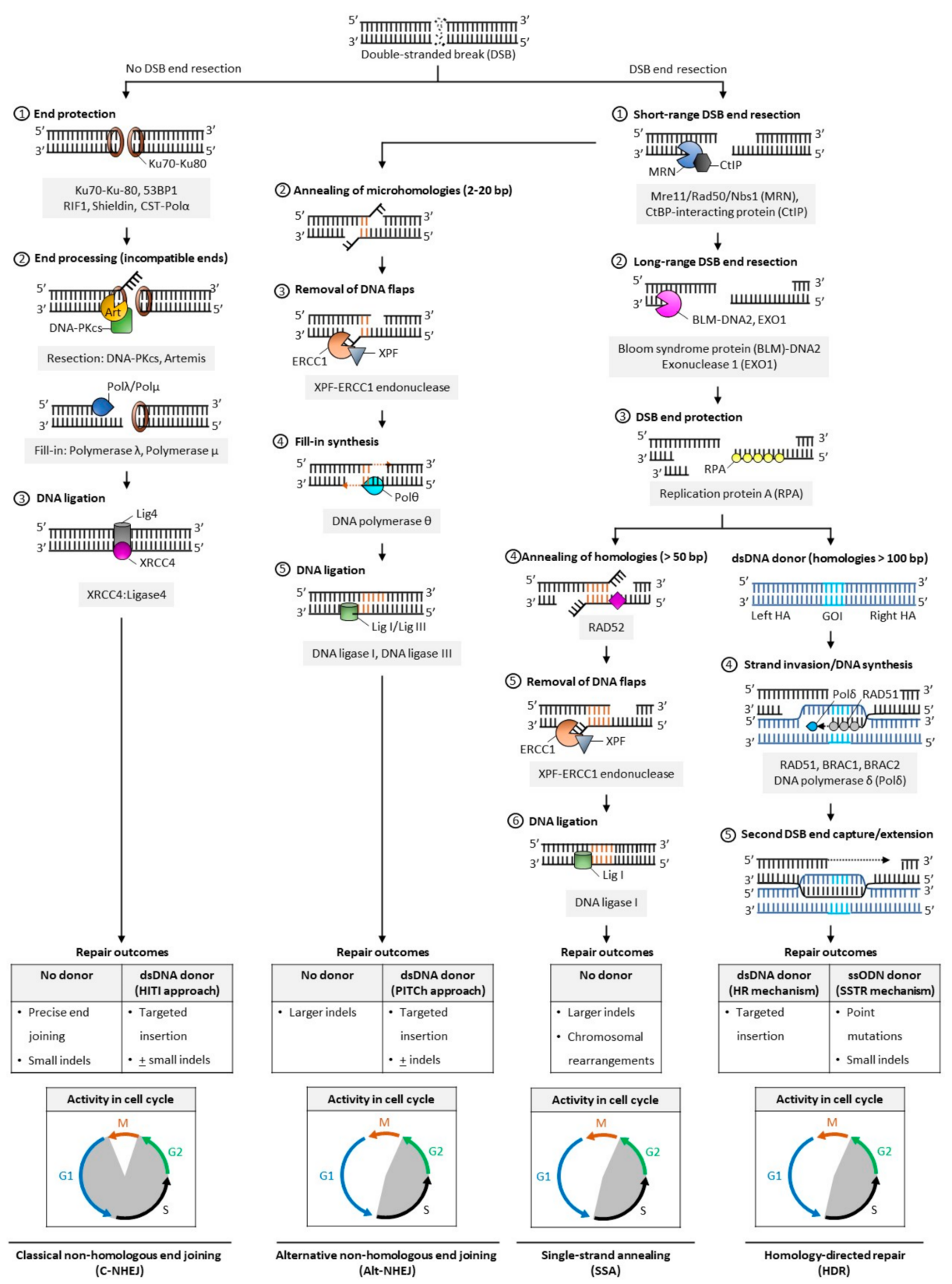

Figure 2. Pathways of DNA double-stranded break repair. Double-stranded breaks (DSBs) are introduced by engineered nucleases at the chosen genomic locus to stimulate endogenous cellular DNA repair mechanisms and promote various repair outcomes. In mammalian cells, DNA DSBs are repaired by classical non-homologous end-joining (C-NHEJ), alternative non-homologous end-joining (alt-NHEJ, also known as MMEJ), single strand annealing (SSA), or homology-directed repair (HDR) pathways. In the absence of donor templates, precise end joining, insertions and deletions (indels), and chromosomal rearrangements may be observed. Addition of a donor DNA template during repair can be used to install and correct point mutations, or knock-in larger DNA sequences. Classic NHEJ does not require template DNA and is the primary repair pathway in cells, whereas alt-NHEJ, SSA, and HDR are known to be active during the S and G2 phases of the cell cycle. Abbreviations: 53BP1: p53-binding protein 1; bp: base pairs; BRAC1: breast cancer type 1; BRAC2: breast cancer type 2; CtBP: C-terminal binding protein; DNA-PKcs: DNA-dependent protein kinase, catalytic subunit; dsDNA: double-stranded DNA; ERCC1: excision repair cross-complementation group 1; GOI: gene of interest; Mre11: meiotic recombination 11; Nbs1: Nijmegen breakage syndrome 1; RAD50/51/52: radiation sensitive 50/51/52; RIF1: Ras relate protein (Rap)interacting factor 1; CST-Pol $\alpha$ : CTC1-STN1-TEN1 (CST)-Polymerase $\alpha$; HITI: homology-independent targeted insertion; HR: homologous recombination; indels: insertion and deletion; PITCh: precise integration into target chromosome; ssODN: single-strand oligodeoxynucleotide; SSTR: single strand template repair; XPF: xeroderma pigmentosum complementation group F; XRCC4: X-ray repair cross completing protein 4. 
The classic form of NHEJ is operational throughout the cell cycle, except mitosis, and quiescent HSPCs largely rely on this mechanism to repair DSB lesions [48-50]. Unlike other DSB repair pathways that require DNA end resection at the break site to expose the homology required for repair, broken DNA ends containing no or limited sequence homology (0-4 bp) are ligated in C-NHEJ, and resection is thus not required. Both ends of DSBs are protected from extensive resection by high-affinity binding of Ku70/80 heterodimer complexes [51] and other end protection proteins including the DNA damage response TP53 binding protein 1 (53BP1) and its effectors (RAP1-interacting factor 1 [RIF1], CST complex-polymerase- $\alpha$ [CST-Pol $\alpha$ ] and the shieldin complex). Compatible DNA ends, such as blunt ends generated by Cas9, are often directly ligated by the XRCC4-DNA ligase 4 (XRCC4:LIG4), with the enhancing activity of XRCC4-like factor (XLF) or paralogue of XRCC4/XLF (PAXX). Incompatible ends, such as $5^{\prime} / 3^{\prime}$-overhangs or $3^{\prime}$-recessed DNA ends, require processing by the Artemis-DNA-PKcs nuclease complex to trim noncomplementary end structures, or by $\operatorname{Pol} \mu$, Pol $\lambda$, and Tdt polymerases to add complementary nucleotides to favor XRCC4:LIG4-mediated ligation. In the absence of donor DNA, the original DNA sequence is generally restored, but limited sequence alterations (e.g., small indels) may also occur at the repair junctions, resulting in silent changes or frameshift mutations leading to target gene inactivation. When a donor sequence is added in vivo along with CRISPR/Cas and gRNA constituents, C-NHEJ can also mediate targeted integration at sites of Cas9-induced DSBs; however, a small percentage of stably integrated sequences may occur in the reverse (undesired) orientation (Figure 2).

The other DSB repair pathways (alt-NHEJ, SSA, and HDR) are known to be active during the $S$ and G2 phases of the cell cycle. They share a first $5^{\prime}$-to- $3^{\prime}$ end short-range resection step catalyzed by the Mre11/Rad50/Nbs1 (MRN) endonuclease complex in conjunction with the $\mathrm{CtBP}$-interacting protein $(\mathrm{CtIP})$. This step requires cyclin dependent kinases 1 and 2 (CDK1/2) to phosphorylate and activate CtIP, and is thus limited to the active phases of the cell cycle [52,53]. Recruitment of CtIP to MRN facilitates the removal of $\mathrm{Ku} 70-\mathrm{Ku} 80$ proteins from DSB ends and promotes the dephosphorylation of 53BP1, which in turn inhibits repair by C-NHEJ [54]. This process initially generates $3^{\prime}$ single-stranded overhangs. When short (2-20 bp, most often 3-8 bp) complimentary base pair microhomologies internal to both broken ends are exposed following resection, the broken ends can be repaired by the alt-NHEJ mechanism, involving the annealing of microhomologies, removal of extraneous heterologous DNA flaps by the XPF-ERCC1 endonuclease, fill-in synthesis of the flanking single-stranded regions by DNA Pol $\theta$, and sealing by DNA ligases I and III [55-57]. Because heterologous flaps flanking the annealed regions of microhomologies are cleaved and lost during alt-NHEJ repair, this pathway is inherently more mutagenic than the classic form of NHEJ. When a donor DNA is added, this repair mechanism can also be exploited for gene knock-in at targeted genomic loci (Figure 2).

In SSA- and HDR-mediated DSB repair, more extensive resection is required. These pathways are thus considerably slower than classical NHEJ or alt-NHEJ mechanisms. The Bloom syndrome protein (BLM)-DNA2 and exonuclease 1 (EXO1) mediate this process, and the replication protein A (RPA) binds the resultant single stranded DNA with high affinity to protect its integrity [58,59]. In SSA, the extended resection exposes longer (>50 bp) sequences of homologies that are uniquely annealed in a RAD52-dependent manner. Similar to alt-NHEJ, the non-complementary tails are then removed by the XPF-ERCC1 endonuclease complex, and the remaining nicks are sealed by DNA ligase 1 [60]. In a normal cellular context, the SSA repair mechanism results in the obligate deletion of a larger sequence between homologous repeats and may promote chromosomal rearrangements (Figure 2) [60].

In HDR [61], RAD51 recombinase is recruited in an ATP-dependent manner to RPAcoated single-stranded DNA, forming a RAD51-DNA nucleoprotein filament. This process is mediated by BRACA2, which is recruited to DNA DSBs by PALB2 and BRAC1 in humans [62-64]. The RAD51 ssDNA filament then locates a homologous DNA template. The template is generally a double-stranded sister chromatid available in late S/G2 phases 
of the cell cycle $[52,65,66]$, or can be provided exogenously in genome editing applications in the form of a double-stranded donor flanked by homology arms. A homology tract of more than $100 \mathrm{bp}$ is typically required as a template to initiate repair by homologous recombination. When complementary ssODN are used as DNA donors, DSBs are processed by a distinct mechanism, the single-strand template repair (SSTR) pathway, which is independent of RAD51 but requires an operative Fanconi anemia (FA) pathway and at least two RAD51 paralogs (RAD51C and XRCC3) [67]. In HDR, the ssDNA filament then invades the homologous region to form a displacement (D)-loop where the template DNA is copied by DNA polymerase $\delta(\mathrm{Pol} \delta)$. The second DSB end is eventually captured by the invading strand, forming a DNA intermediate with two Holliday junctions. This structure undergoes gap repair DNA filling and ligation, and is ultimately resolved at both Holliday junctions in a non-crossover or crossover mode. In some cases, repair can occur by synthesis dependent strand annealing (SDSA), in which the newly replicated DNA dissociates from the template without the formation of a Holliday junction, or by break-induced replication (BIR), when the second DSB end is absent or cannot be found; however, the role of these pathways in genome editing has not been defined (Figure 2). Owing to the obligate use of a donor template sequence, HDR is considered error-free and is generally the preferred pathway for genome editing. Site- and orientation-specific integration at a chosen locus, either upstream of an endogenous promoter or within a safe harbor locus, is a commonly desired repair outcome for therapeutic applications. However, the low frequency of HDR in primary cells, especially long-term repopulating HSCs, remains a challenge to achieving high rates of targeted gene insertion by HDR $[48,68]$.

\subsection{Cellular Delivery of Gene Editing Tools}

Safe and effective cellular delivery of engineered nucleases, gRNAs, and template sequences constitutes a key step in the process of gene editing. For ex vivo genome editing, approaches for the delivery of the required constituents within target cells can be broadly classified into viral vectors, electroporation, and cell-penetrating peptides [69]. In primary cells, including HSPCs, nucleases and the associated gRNAs are most effectively delivered by electroporation of mRNA molecules or as an RNP complex between gRNAs and the nuclease (e.g., Cas9) protein. Unlike transfection of DNA plasmid molecules, this approach results in limited cytotoxicity to HSPCs. In addition, the short half-life of the complex temporally limits the nuclease activity and the likelihood of genome editing at off-target loci [70].

Donor template delivery has also been a significant challenge for gene editing of HSPCs, as electroporation of dsDNA is highly toxic. Several alternative delivery platforms have been successfully been used, including ssODNs co-delivered with Cas9 [27,71-73]. For larger gene insertions, viral vectors are very effective, including integrase deficient lentivirus (IDLV) [74-76] and adeno associated virus serotype 6 (AAV6) [77]. There are several caveats, however, to the delivery of donor templates using virus-based systems, including DNA packaging capacity, which is limited by the viral capsid size, and off-target integration of viral genes [78].

\section{Pre-Clinical Development of HDR-Mediated Gene Editing in HSPCS}

Few genetic diseases, such as sickle cell disease (SCD), thalassemia, and Fanconi anemia (FA), can be cured by NHEJ-mediated incorporation of frameshift indels for disruption of open reading frames. However, the surgical precision provided by HDR-based gene correction or addition is preferred for most inherited disorders. In this section, we discuss preclinical studies utilizing HDR-mediated genome editing in HSPCs from healthy subjects or patients with inherited disorders amenable to treatment by transplantation of edited HSPCs (Table 1). 
Table 1. HDR-mediated genome editing in HSPCs for inherited disorders.

\begin{tabular}{|c|c|c|c|c|c|}
\hline Disease & Study & HSPC Source & Gene Editing System & Editing Efficiency at Target Locus & Ref. \\
\hline \multirow{7}{*}{ SCD } & \multirow{4}{*}{ In vitro } & BM, SCD subjects & ZFN mRNA + IDLV & $18.4 \% H B B$ & [74] \\
\hline & & BM, SCD subjects & Cas9 mRNA + IDLV & $20 \% H B B$ & [75] \\
\hline & & Blood, SCD subjects & Cas9 RNP + ssODN & $25 \% H B B$ & [27] \\
\hline & & $\mathrm{mPB}, \mathrm{SCD}$ subjects & Cas9 RNP + AAV6 & $50 \% H B B$ & [79] \\
\hline & \multirow{3}{*}{ In vivo } & $\mathrm{CB}$, healthy subjects & ZFN mRNA + IDLV & $\begin{array}{l}\left.0.21 \% \text { HBB ( } 1^{\circ} \text { NSG BM }\right) \\
\left.0.27 \% \text { HBB ( } 1^{\circ} \text { NSG spleen }\right)\end{array}$ & [74] \\
\hline & & $\mathrm{mPB}$, healthy subjects & Cas9 RNP + ssODN & $2.3 \%$ HBB (1 NSG BM) & [27] \\
\hline & & $\mathrm{mPB}$, healthy subjects & Cas9 RNP + AAV6 & $\begin{array}{l}\left.90 \% \text { HBB ( } 1^{\circ} \text { NSG BM + selection }\right) \\
\left.3.5 \% \text { HBB (1 } 1^{\circ} \text { NSG BM-selection }\right)\end{array}$ & [79] \\
\hline \multirow{8}{*}{ SCID-X1 } & \multirow{4}{*}{ In vitro } & \multirow{2}{*}{ CB, SCID-X1 subject } & ZFN mRNA + IDLV & $>20 \%$ IL2RG & \multirow{2}{*}{80} \\
\hline & & & ZFN mRNA + AAV6 & $>50 \%$ IL2RG & \\
\hline & & $\mathrm{mPB} / \mathrm{CB}$, healthy subjects & Cas9 RNP + AAV6 & $45 \%$ IL2RG & [81] \\
\hline & & $\mathrm{mPB}, \mathrm{SCID}-\mathrm{X} 1$ subjects & Cas9 RNP + AAV6 & $44.5 \%$ IL2RG & \\
\hline & \multirow{4}{*}{ In vivo } & \multirow{2}{*}{ CB, SCID-X1 subject } & ZFN mRNA + IDLV & $5 \%$ IL2RG $\left(1^{\circ}\right.$ NSG BM HSPCs $)$ & \multirow{2}{*}{ [80] } \\
\hline & & & ZFN mRNA + AAV6 & $>25 \%$ IL2RG (1 NSG BM HSPCs) & \\
\hline & & $\mathrm{CB}$, healthy subjects & Cas9 RNP + AAV6 & $\begin{array}{l}25.5 \% \text { IL2RG }\left(1^{\circ} \mathrm{NSG} \mathrm{BM}\right) \\
9.5 \% \text { to } 20 \% \text { IL2RG }\left(2^{\circ} \mathrm{NSG} \mathrm{BM}\right)\end{array}$ & \multirow[t]{2}{*}{ [81] } \\
\hline & & $\mathrm{mPB}, \mathrm{SCID}-\mathrm{X} 1$ subjects & Cas9 RNP + AAV6 & Corrected IL2RG (1 NSG spleen) & \\
\hline \multirow{4}{*}{ X-CGD } & \multirow{2}{*}{ In vitro } & mPB, X-CGD subjects & ZFN mRNA + AAV6 & $\begin{array}{l}\text { 15\% AAVS1, gp91 } 9 \text { phox expression in } \\
\text { HSPC-derived myeloid cells }\end{array}$ & [82] \\
\hline & & mPB, X-CGD subjects & Cas9 mRNA + ssODN & $\begin{array}{l}31 \% \text { AAVS1, gp91 } \\
\text { HSox expression in } \\
\text { HSP-derived myeloid cells }\end{array}$ & [71] \\
\hline & & $\mathrm{mPB}, \mathrm{X}-\mathrm{CGD}$ subjects & ZFN mRNA + AAV6 & 10.7\% AAVS1, gp91phox $\left(1^{\circ}\right.$ NSG BM) & {$[82]$} \\
\hline & In vivo & $\mathrm{mPB}, \mathrm{X}-\mathrm{CGD}$ subjects & Cas9 mRNA + ssODN & $\begin{array}{l}15.6 \% \text { AAVS1, gp91 } 9 \text { phox }\left(1^{\circ} \text { NSG PB }\right) \\
16.5 \% \text { AAVS1, gp91 } \\
\text { phox }\left(1^{\circ} \text { NSG BM }\right)\end{array}$ & [71] \\
\hline \multirow{5}{*}{ XHIM } & \multirow{3}{*}{ In vitro } & \multirow{3}{*}{ mPB, XHIM subjects } & TALEN + AAV6 & $13.2 \%$ CD $40 L G, 5^{\prime}$ UTR & \multirow{3}{*}{ [83] } \\
\hline & & & Cas9 mRNA + AAV6 & $16.2 \%$ CD $40 L G, 5^{\prime}$ UTR & \\
\hline & & & Cas9 RNP + AAV6 & $20.8 \%$ CD $40 L G, 5^{\prime}$ UTR & \\
\hline & \multirow{2}{*}{ In vivo } & \multirow{2}{*}{ mPB, XHIM subjects } & $\begin{array}{l}\text { TALEN }+ \text { AAV } 6 \pm \\
\text { adeno helper protein }\end{array}$ & \multirow{2}{*}{$\begin{array}{l}\text { Average of all editing strategies: } \\
4.4 \% \text { CD } 40 L G\left(1^{\circ} \text { NSG BM). No }\right. \\
\text { increased editing with addition of } \\
\text { adeno helper protein }\end{array}$} & \multirow[t]{2}{*}{ [83] } \\
\hline & & & $\begin{array}{l}\text { Cas9 RNP + AAV6 } \pm \\
\text { adeno helper protein }\end{array}$ & & \\
\hline \multirow{3}{*}{$\mathrm{SCN}$} & \multirow{2}{*}{ In vitro } & mPB, healthy subjects & Cas9 RNP + AAV6 & $30 \%$ ELANE (exon 4 gRNA) & \multirow{2}{*}{ [84] } \\
\hline & & $\mathrm{BM}, \mathrm{SCN}$ subjects & Cas9 RNP + AAV6 & $\begin{array}{l}30 \% \text { ELANE (exon } 4 \text { gRNA) } \\
20 \% \text { ELANE (L172P gRNA) }\end{array}$ & \\
\hline & In vivo & $\mathrm{BM}, \mathrm{SCN}$ subjects & Cas9 RNP + AAV6 & $\begin{array}{l}\text { 3.1\% ELANE-corrected neutrophils } \\
\left(1^{\circ} \mathrm{NOG}-\mathrm{EXL} \mathrm{BM}\right)\end{array}$ & [84] \\
\hline \multirow{3}{*}{ WAS } & \multirow[t]{2}{*}{ In vitro } & $\mathrm{mPB}$, healthy subjects & Cas9 RNP + AAV6 & $\begin{array}{l}69 \% \text { WAS, bulk CD34 + cells } \\
67.3 \% \text { WAS, sorted HSCs (day 7) } \\
58.8 \% \text { WAS, sorted HSCs (day 14) }\end{array}$ & \multirow[t]{2}{*}{ [85] } \\
\hline & & $\mathrm{mPB} / \mathrm{BM}, \mathrm{WAS}$ subjects & Cas9 RNP + AAV6 & $\begin{array}{l}46.4 \% \text { WAS, CD34 + cells (ddPCR) } \\
45.5 \% \text { WAS, CD34 + cells (flow) }\end{array}$ & \\
\hline & In vivo & $\mathrm{mPB} / \mathrm{BM}, \mathrm{WAS}$ subjects & Cas9 RNP + AAV6 & $\begin{array}{l}36.8 \% \text { WAS }\left(1^{\circ} \text { NSG BM }\right) \\
16 \% \text { WAS }\left(2^{\circ} \text { NSG BM }\right)\end{array}$ & [85] \\
\hline
\end{tabular}


Table 1. Cont.

\begin{tabular}{llllll}
\hline Disease & Study & HSPC Source & Gene Editing System & Editing Efficiency at Target Locus & Ref. \\
\hline \multirow{3}{*}{ LSD } & \multirow{2}{*}{ In vitro } & $\mathrm{CB} / \mathrm{mPB}$, healthy subjects & Cas9 RNP + AAV6 & $28 \%$ CCR5 (PGK-IDUA) & [86] \\
\cline { 2 - 6 } & \multirow{2}{*}{ In vivo } & $\mathrm{mPB} / \mathrm{CB}$, healthy subjects & Cas9 RNP + AAV6 & $\sim 50 \%$ HBA1 $(L A L$ donor) & [87] \\
\cline { 2 - 6 } & $\mathrm{mPB} / \mathrm{CB}$, healthy subjects & Cas9 RNP + AAV6 & $5-6 \%$ CCR5, PGK-IDUA $\left(1^{\circ} \mathrm{NSG} \mathrm{BM}\right)$ & {$[86]$} \\
\hline
\end{tabular}

Abbreviations: AAV6: adeno-associated virus 6; BM: bone marrow; PB: peripheral blood; IDLV: integration-deficient lentivirus; tNGFR: truncated nerve growth-factor receptor; ssODN: single-stranded oligonucleotide; RNP: ribonucleoprotein; IL2R: interleukin-2 receptor common gamma chain; CB:, cord blood; mPB: mobilized peripheral blood; UTR: untranslated region; NSG: NOD/SCID/IL-2r $\gamma^{\text {null; }}$ NOG: NOD.Cg-Prkdcscid Il2rgtm1Sug/JicTac; NOG-EXL: NOD.Cg-Prkdcscid Il2rgtm1Sug Tg(SV40/HTLV-IL3, CSF2)10-7Jic/JicTac; HBB: beta-globin gene; CYBB: cytochrome B-245 beta chain; CD40LG: CD40 ligand; CCR5: C-C chemokine receptor type 5; IDUA: alpha-L-iduronidase; LAL: lysosomal acid lipase; SCD: sickle cell disease; ZFN: zinc-finger nuclease; TALEN: transcription-activator like effector nuclease; SCID-X1: X-linked severe combined immuno-deficiency; X-CGD: X-linked chronic granulomatous disorder; XHIM: X-linked hyper immunoglobulin (Ig)M syndrome; SCN: severe congenital neutropenia; WAS: Wiskott-Aldrich syndrome; LSD: lysosomal storage disorders; HSPCs: hematopoietic stem/progenitor cells; HBA1: hemoglobin A1; PGK: phosphoglycerate kinase; ELANE: elastase, neutrophil expressed.

\subsection{Sickle Cell Disease (SCD)}

Targeting the causative sickle mutation within the HBB gene by eliciting HDR DNA repair mechanisms in HSPCs has been challenging. Several groups have shown highly successful rates (up to $50 \%$ ) of editing in vitro in HSPCs derived from SCD subjects' marrow or peripheral blood $[27,74,75,79]$. However, transplant studies in NOD/SCID/IL-2r $\gamma^{\text {null }}$ (NSG) mice to assess in vivo engraftment and long-term function of edited HSPCs (derived from healthy subjects and edited to introduce the sickle mutation due to limited availability of HSPCs from SCD patients) have thus far achieved less than $5 \%$ editing in engrafted human cells in the absence of pre-transplant selection of edited HSPCs $[27,74,79]$. By applying a GFP reporter selection system, a median of $90 \%$ edited human cells was attained within the marrow of NSG mice after transplantation, but marker-free selection will be necessary for clinical translation of these therapies [79] (Table 1).

\subsection{X-Linked Severe Combined Immunodeficiency (SCID-X1)}

SCID-X1 is a primary immunodeficiency caused by mutations in interleukin-2 receptor common gamma chain (IL2RG) gene resulting in loss of T-cell, natural killer (NK) cell, and B-cell function. Although allogeneic bone marrow transplant is curative, HLA-donor matching and complications from graft-versus-host-disease present therapeutic challenges. Targeted gene addition within the IL2RG locus in CD34+ HSPCs, first shown by the Naldini lab, achieved efficiencies of approximately $6 \%$ in vitro using ZFNs and IDLV for template delivery [76]. A second study with an optimized ZFN design improved HDRmediated editing in SCID-X1 patient HSPCs to over $20 \%$ in vitro. When the IDLV donor DNA vehicle was substituted with AAV6 donor vectors, up to 50\% HDR-edited cells were observed within the CD34+ CD133 - cellular compartment, with over $20 \%$ editing of HSPCs transplanted into NSG mice [80]. More recently, the Porteus lab used a Cas9 RNP / AAV6 editing system for targeted integration of a complete cDNA at the endogenous IL2RG translational start site [81]. In healthy donor cord blood (CB) or mobilized peripheral blood (mPB) CD34+ HSPCs, they achieved median in vitro HDR editing rates of $45 \%$ and significant persistence of edited cells long-term after transplantation in primary and secondary NSG animals. Importantly, marrow CD34+ cells from six independent SCID-X1 patients were also edited. Ex vivo editing frequencies were comparable to healthy donor HSPCs, and mice transplanted with cells from one patient had only corrected IL2RG cDNA within the spleen with significant multilineage correction compared to unedited HSPC [81] (Table 1). Globally, these studies provide proof-of-concept that current approaches for targeted integration at the IL2RG locus may enable correction of the SCID-X1 phenotype in affected patients. 


\subsection{X-Linked Chronic Granulomatous Disease (X-CGD)}

The $\mathrm{X}$-linked form of CGD (X-CGD) is a rare primary immunodeficiency caused by mutations in the CYBB gene that encodes gp91phox, a subunit of NADPH oxidase 2 (NOX2). Individuals born with CGD have inherited phagocyte dysfunction and increased susceptibility to bacterial and fungal microorganisms, formation of chronic granulomas, and poor wound healing. Initial attempts to edit X-CGD HSPCs used engineered ZFNs for targeted insertion of a functional gp91 ${ }^{\text {phox }} \mathrm{CDNA}$ within the genomic "safe harbor" AAVS1 locus [82]. Investigators achieved $15 \%$ gp $91^{\text {phox }}$ protein expression in vitro and an average of $10.7 \%$ of human CD45 + (hCD45) cells in NSG bone marrow expressed gp91phox eight weeks post engraftment [82]. A follow-up study used Cas9 and an ssODN donor DNA to correct a single base mutation (C676T) within the CYBB gene of CD34 + HSPCs from an X-CGD patient. In this approach, the repaired CYBB gene remains under the control of its endogenous promoter, avoiding concerns over suboptimal expression from an ectopic promoter. Approximately $31 \%$ gp $91^{\text {phox }}$ expression was observed after myeloid differentiation of edited HSPCs in vitro. Transplant of CYBB C676T corrected HSPCs into NSG mice resulted in $16.5 \%$ of hCD45+ derived from edited CD34+ cells expressing gp91 ${ }^{\text {phox }}$ within the mouse bone marrow with partial restoration of NOX2 activity [71] (Table 1). Overall, this study demonstrated feasibility of a targeted approach for gene mutation repair in a monogenic inherited disorder.

\subsection{X-Linked Hyper-Immunoglobulin (Ig)M Syndrome (XHIM)}

Adaptive immune cell function, particularly T- and B-cell interactions, relies in part on the association of CD40-CD40 ligand (CD40L). CD40L on T-cells, expressed after T-cell receptor (TCR) engagement, activates CD40 on B-cells, resulting in antibody classswitching and long-term memory response. Mutations in the CD40LG gene result in recurrent infections and low serum immunoglobulins in XHIM patients. Initial editing rates up to $46 \%$ within exon 1 of the endogenous CD40LG gene were achieved in activated CD4 + T-cells. Average editing up to $29 \%$ of XHIM patient CD4+ cells successfully restored CD40L expression post-T-cell activation, CD40 binding, and B-cell class switching [88]. While these findings potentially pave the way for an adoptive T-cell based therapy, editing of HSPCs from MPB of XHIM patients has also been achieved. Evaluation of CD40LG edited HPSCs in NSG mice 12-20 weeks post-transplant revealed an average integration of $4.4 \%$ across all editing platforms tested, comparable to editing rates achieved in other primary immune deficiencies (PIDs) [83] (Table 1).

\subsection{Severe Congenital Neutropenia (SCN)}

Severe congenital neutropenia syndromes are a group of PIDs impacting neutrophil function, caused by mutations inherited in an autosomal dominant, recessive, or X-linked manner. The most common causal gene, ELANE, encodes neutrophil elastase, and can harbor several hundred different mutations. Patients with SCN have severely decreased absolute neutrophil counts (ANC), resulting in frequent bacterial infections and a high risk of developing myelodysplastic syndrome. While treatment with G-CSF can improve neutrophil function and mobilization, gene editing has the potential to be curative. Tran and colleagues employed two different CRISPR/Cas9 RNPs in combination with AAV6 to repair both a specific ELANE ${ }^{\mathrm{L} 172 \mathrm{P}}$ point mutation as well as targeting exon 4 , in which the majority of ELANE mutations are found [84]. HDR efficiencies of 30\% were achieved at exon 4 of ELANE in HSPCs from both healthy and SCN subjects, and 20\% HDR-mediated correction was observed at the mutant ELANE ${ }^{\mathrm{L} 172 \mathrm{P}}$ alleles in bone marrow $\mathrm{CD} 34+$ cells from affected patients. Neutrophils differentiated in vitro from edited HSPCs produced similar amounts of reactive oxygen species (ROS), exhibited normal phagocytosis, efficient bacterial killing, and production of neutrophil extracellular traps (NETs). At four weeks post-transplant of humanized NOG-EXL mice (expressing human GM-CSF and IL-3), only ELANE corrected HSPCs were able to functionally differentiate into neutrophils [84] (Table 1). 


\subsection{Wiskott-Aldrich Syndrome (WAS)}

Wiskott-Aldrich Syndrome (WAS) is an X-linked primary inherited immunodeficiency characterized by microthrombocytopenia and lymphocyte dysfunction. Affected patients have increased incidence of infectious and autoimmune complications. Mutations in the WAS gene result in abnormal WAS protein (WASp), causing disruption of the actin cytoskeleton and impaired cellular mobility and interactions. Both CRISPR/Cas9 and ZFNs platforms were first shown to facilitate HDR-mediated gene editing at the WAS locus in a K562 cellular model [89]. In a subsequent study, Rai and colleagues used Cas9 RNP and AAV6 donor vectors to mediate targeted knock-in of a PGK-GFP expression cassette or a codon divergent promoterless WAS cDNA downstream of the ATG translational start codon of the WAS gene in primary HSPCs. In CD34+ cells from healthy subjects, more than half $(58.8 \%)$ of HSCs sorted from the bulk cellular population expressed GFP at culture day 14, indicating stable HDR-mediated integration of the reporter cassette in the most primitive HSPC compartment. In $\mathrm{MPB}$ and BM CD34+ cells derived from individuals with WAS, targeted integration and expression of the WAS cDNA were detected in $46 \%$ of treated HSPCs, surpassing expression levels (33\%) attained with the standard lentivirus-based gene transfer strategy previously used by these investigators. Transplant of edited WAS HSPCs into NSG mice revealed an average of $36 \%$ edited hCD45+ cells expressing WASp, with a substantial increase in percentages of B-, T-, and myeloid cells expressing WASp compared to HSPCs transduced with lentiviral vectors. Gene correction of up to $16 \%$ of targeted long-term repopulating-HSCs was also determined by secondary transplantation, providing comprehensive preclinical evidence of efficacy of a CRISPR-based gene editing approach for the treatment of subjects with WAS [85] (Table 1).

\subsection{Lysosomal Storage Disorders}

Inherited lysosomal storage disorders (LSDs) are a group of metabolic diseases in which enzyme deficiencies result in abnormal accumulation of metabolic biproducts. Mucopolysaccharidosis type I (MPSI) results from mutations in the iduronidase gene (IDUA). Affected patients develop severe muscle and neurological complications due to the buildup of glycosaminoglycan (GAG). A flexible Cas9/AAV6 platform based on HDR-mediated targeted integration of a PGK-IDUA cassette at the CCR5 safe harbor site recently showed ex vivo fraction of targeted alleles of $28 \%$ in healthy donor HSPCs that declined to 5-6\% in NSG engrafted cells, indicating a marked decrease in engraftment potential after gene editing [86]. Nevertheless, edited IDUA HSPCs were able to phenotypically and functionally correct skeletal and neurological defects including a significant reduction of GAG excretion in NSG-IDUA ${ }^{X / X}$ mice, a novel mouse model of MPSI [86]. Using a similar Cas9/AAV6 approach, Pavani and colleagues targeted the lysosomal acid lipase ( $L A L)$ transgene, associated with the LSD Wolman disease, into the alpha-globin loci (HBA1 and $H B A 2$ ) of healthy donor HSPCs [87]. This approach achieved more than $50 \%$ knock-in efficiency, with $87 \%$ of burst-forming unit-erythroid (BFU-E) colonies showing $L A L$ integration and secretion of LAL enzyme. Transplant into NSG mice resulted in engraftment of edited HSPCs, decreasing over 16 weeks to less than $10 \%$ of hCD45+ cells. Ex vivo erythroid differentiation of human CD34+ cells isolated from the BM of engrafted mice demonstrated LAL enzyme production in differentiated erythroblasts [87]. Together, these studies provide support to further develop HDR-based gene editing strategies in HSPCs for the treatment of lysosomal storage disorders (Table 1).

\section{Strategies to Improve HDR-Mediated Gene Editing in HSPCs}

\subsection{Modulation of DNA Repair and Cell Cycle Pathways with Small Molecules}

Addition of small molecules targeting DNA repair pathways or cell cycle regulators during the ex vivo editing process has been widely used to improve HDR-mediated gene editing in HSPCs. Small molecules have an advantage over other strategies due to their general ease of use and possible benefits regardless of the genetic target. The majority of small molecules that are currently being used fall within five general categories: 
small molecule inhibitors of NHEJ proteins, small molecules that directly promote HDR, molecules modulating the cell cycle, molecules targeting chromatin structure, and those with undefined mechanisms. As summarized in Table 2, small molecules have been used in a variety of mammalian cell lines with variable effects on HDR. Differences in species, reporter systems, which may or may not use a nuclease, and target genes are possible sources of variability. Importantly, very few of these small molecules have been tested in hematopoietic cells, and fewer in primary human CD34+ HSPCs in the context of CRISPR/Cas9. The following sections will focus primarily on small molecules previously tested in cells of hematopoietic origin.

Table 2. Small molecules tested in hematopoietic cells to improve HDR-mediated genome editing.

\begin{tabular}{|c|c|c|c|c|c|c|c|}
\hline Molecule & Pathway & Molecule Target & Cells & Editing System & $\begin{array}{l}\text { Target } \\
\text { Locus }\end{array}$ & HDR Editing Results & Ref. \\
\hline \multirow{2}{*}{ NU7441 } & \multirow{2}{*}{ NHEJ } & \multirow{2}{*}{ DNA-PK inhibitor } & K562 & Cas9 RNP + AAV6 & $C D 45$ & $\sim 2.5$-fold increase & \multirow{2}{*}{ [90] } \\
\hline & & & CD34+ & Cas9 RNP + AAV6 & $C D 45$ & $\sim 2$-fold increase & \\
\hline \multirow{4}{*}{ NU7026 } & \multirow{4}{*}{ NHEJ } & \multirow{4}{*}{ DNA-PK inhibitor } & K562 & Cpf1 + ssODN-TNS & HPRT & $\sim 4$-fold increase & \multirow{3}{*}{ [91] } \\
\hline & & & CD4+ & Cpf1 + ssODN-TNS & HPRT & 3-fold increase & \\
\hline & & & CD34+ & Cpf1 + ssODN-TNS & HPRT & 1.7-fold increase & \\
\hline & & & K562 & Cas9 RNP + AAV6 & CD45 & No increase & [90] \\
\hline M3814 & NHEJ & DNA-PK inhibitor & K562 & Cas9+ ssODN & FRMD7 & $\sim 4$-fold increase & [72] \\
\hline \multirow{3}{*}{ SCR7 } & \multirow{3}{*}{ NHEJ } & \multirow{3}{*}{ Inhibitor of ligase IV } & K562 & Cas9 RNP + AAV6 & CD45 & No increase & \multirow{2}{*}{ [90] } \\
\hline & & & CD34+ & Cas9 RNP + AAV6 & $C D 45$ & No increase & \\
\hline & & & CD34+ & Cas9 RNP + ssODN & $H B B$ & No increase & {$[27]$} \\
\hline \multirow{3}{*}{ RS-1 } & \multirow{3}{*}{ HDR } & \multirow{3}{*}{ RAD51 agonist } & K562 & Cas9 RNP + AAV6 & CD45 & 2.1-fold increase & \multirow{2}{*}{ [90] } \\
\hline & & & CD34+ & Cas9 RNP + AAV6 & $C D 45$ & No increase & \\
\hline & & & K562 & Cas9 RNP + dsDNA & $\begin{array}{l}\text { LAMP1 } \\
\text { FBL }\end{array}$ & No increase & [73] \\
\hline Nocodazole & Cell cycle & $\begin{array}{l}\text { Inhibition of } \\
\text { microtubule } \\
\text { polymerization }\end{array}$ & K562 & Cas9 RNP + dsDNA & $\begin{array}{l}\text { LAMP1 } \\
\text { FBL } \\
\text { RAB11A } \\
\text { TOMM20 } \\
\end{array}$ & $\begin{array}{l}\sim 5-10 \% \text { increase in FBL, } \\
\text { RAB11A, and TOMM20 }\end{array}$ & [73] \\
\hline RO-3306 (RO) & Cell cycle & CDK1 inhibitor & CD34+ & hGemCas9 + AAV6 & $H B B$ & $\begin{array}{l}\text { Increase in ratio } \\
\text { HDR/NHEJ: } 4 \text {-fold } \\
\text { (in vitro), } 7 \text {-fold (in vivo, } \\
\text { NSG mice) }\end{array}$ & [68] \\
\hline \multirow[t]{3}{*}{ XL413 } & \multirow[t]{3}{*}{ Cell cycle } & \multirow[t]{3}{*}{$\begin{array}{l}\text { CDC7 inhibitor, } \\
\text { extends S-phase }\end{array}$} & K562 & Cas9 RNP + dsDNA & $\begin{array}{l}\text { SMC1A } \\
\text { LAMP1 } \\
\text { HIST1H2BJ } \\
\text { NPM1 } \\
\text { FUS } \\
\text { TOMM20 } \\
\text { FBL } \\
\text { RAB11A } \\
\end{array}$ & $\begin{array}{l}\sim 1.6 \text { to } 3.5 \text {-fold increase at } \\
\text { all loci }\end{array}$ & \multirow[t]{3}{*}{ [73] } \\
\hline & & & T-cells & Cas9 RNP + dsDNA & $\begin{array}{l}\text { RAB11A } \\
\text { TUBA1B } \\
\text { CLTA }\end{array}$ & $\begin{array}{l}\text { Increase at all loci in a dose } \\
\text { dependent manner }\end{array}$ & \\
\hline & & & CD34+ & Cas9 RNP + ssDNA & $\begin{array}{l}\text { HBB } \\
\text { TOMM20 }\end{array}$ & Slight increase & \\
\hline L755507 & Unknown & $\begin{array}{l}\text { ß3-adrenergic receptor } \\
\text { agonist }\end{array}$ & K562 & Cas9 RNP + AAV6 & $C D 45$ & 1.5-fold increase & {$[90]$} \\
\hline
\end{tabular}

Abbreviations: mPB-HSPC: mobilized peripheral blood-HSPC; TNS: targeted nucleotide substitutions; RNP: ribonucleoprotein; ssODN: single stranded oligonucleotide; PBMCs: peripheral blood mononuclear cells; NSG: NOD/SCID/IL-2r $\gamma^{\text {null }}$; CDC7: cell division cycle 7; CDK1: cyclin-dependent kinase 1; DNA-PK: DNA-protein kinase; HBB: beta-globin gene; HPRT: hypoxanthine phosphoribosyltransferase 1; FRMD7: FERM domain containing 7; SMC1A: structural maintenance of chromosomes 1A; LAMP1: lysosomal associated membrane protein 1; HIST1H2BJ: histone cluster 1 H2B family member J; NPM1: nucleophosmin 1; FUS: FUS RNA binding protein; TOMM20: translocase of outer mitochondrial membrane 20; FBL: fibrillarin; TUBA1B: tubulin alpha 1b; CTLA: cytotoxic T-lymphocyte associated protein 4. 
Small molecule antagonists of the NHEJ pathway are commonly used to promote HDR, but benefits must be weighed against increased cellular toxicity and the potential loss of genomic integrity. DNA-PK inhibitors, including NU7026 and NU7441, can improve HDR rates in a number of different cell lines, such as human iPSCs and MEFs. Gene editing of the chronic myeloid leukemia (CML) cell line K562 and primary CD34+ HSPCs with an AAV2/ 6 donor and Cas9 nuclease in the presence of NU7441 improved the frequency of HDR approximately two-fold, but some cellular toxicity was observed [90]. NU7026 has also been tested, alone or in combination with other small molecules, in hematopoietic cells edited with Cas12a in the presence of an ssODN donor template [91]. This approach improved HDR editing in K562, CD4+ T cells, and CD34+ progenitors, but the total number of HDR-edited CD34+ cells did not exceed $0.63 \%$, and viability was only $65 \%$. More recently, the DNA-PK inhibitor M3814 was also shown to significantly improve editing after a Cas9-induced DSB in K562 cells without significant toxicity or unwanted chromosomal alterations [72]. To date, M3814 has not been tested in primary CD34+ HSPCs. The DNA ligase IV inhibitor, SCR-7, was also tested in K562 and primary CD34+ HSPCs edited with AAV6 and Cas9; unlike previous reports in human cancer cell lines and porcine fibroblasts, SCR-7 did not improve HDR editing in K562 cells or CD34+ HSPCs [27,90].

Small molecules that directly promote the HDR pathway have also been used for genome editing in HSPCs. RS-1 was first identified in a large scale screen of compounds shown to enhance the activity of Rad51 [92]. It was then shown to improve Cas9-mediated HDR in U2OS and HEK293 cells [93]. Cas9 gene editing of K562 cells with a CD45-GFP template in the presence of RS-1 improved HDR approximately two-fold, but this finding was not reproducible in primary CD34+ HSPCs [90]. Similarly, more recent studies in human iPSCs with inducible CRISPR/Cas9 [91] and K562 cells with Cas9 RNP targeting two different genes [73] showed no additional benefit of RS-1. Recently, 26 chemical compounds that share a core structure with RS-1 were tested for their ability to improve HDR in HEK293 cells. One compound, identified as chemical 26, improved integration of a puromycin resistance cassette within the ATG5 gene locus 7.5-fold more than a DMSO control [94].

Cell cycle plays a critical role in DNA repair decisions after induction of DSB within the cellular genome. Quiescent HSPCs do not use HDR [95]. A two-day, low-density culture in medium supplemented with cytokines and small molecules that favor HSPC maintenance and self-renewal, such as prostaglandin E2 (PGE2) [96], StemRegenin1 (SR1) [97], and the pyrimidinone derivative UM171 [98] is thus routinely used to coax HSPCs into cycle and promote more efficient HDR $[99,100]$. However, HSPCs in the active phases of the cell cycle engraft poorly compared to quiescent cells [101]. A two-pronged strategy was recently proposed to address this quandary [95]. Cells were first allowed to cycle in culture medium containing cytokines to promote the accumulation of alleles corrected by HDR, and then reverted back to a G0 quiescent state to maintain stemness and long-term engraftment potential of edited cells. Quiescence was re-induced after gene editing by a three-day culture in medium supplemented with regulators of Wnt (CHIR9901) and mammalian target of rapamycin (mTOR) (rapamycin) pathways [102]. This approach increased the number of HDR editing events by five-fold up to almost $30 \%$ of alleles in HSPCs capable of long-term engraftment in immune-deficient recipient mice, suggesting that HDR-edited stem cells had re-entered G0 and sustained long-term hematopoiesis in vivo [95]. Several strategies have also focused on small molecules that directly modulate regulators of the cell cycle. Many commonly used compounds stall the cell cycle at G2/M-phase, including nocodazole [103], ABT-751 [104] and RO-3306 (RO) [68]. Only RO, which selectively inhibits CDK1, has been tested in peripheral blood stem cells. In combination with a G2/M-phase restricted Cas9-fusion enzyme, hGemCas9 (see Section 4.3), RO significantly decreased the percentage of NHEJ-mediated gene editing within $H B B$; however, no differences in HDR were observed [68]. Importantly, as with NU7441, RO treatment also significantly decreased cell viability. Likewise, it has been shown that addition of nocodazole to mouse LSK progenitors significantly increases apoptosis [105]. Recently, inhibition of the FA pathway repressor CDC7 by a small molecule, XL413, improved HDR in K562 cells regardless of the 
genetic target and with minimal cell toxicity [73]. Mechanistically, XL413 was shown to extend progression through S-phase of the cell cycle. Gene editing using an ssODN donor targeting the HBB locus in HSPCs also increased when cells were treated with XL413, and with minimal toxicity. Studies using alternative donor templates such as AAV6 will be necessary to determine if HDR can also be improved in HSPCs.

An emerging strategy to improve HDR gene editing entails targeting the structure of chromatin DNA with histone deacetylase (HDAC) inhibitors. Acetylation of histone lysine residues decreases their affinity to DNA, opening the chromatin for enhanced accessibility to repair proteins and transcription factors. Although not yet tested in HSPCs, the HDAC inhibitor valproic acid (VPA) was shown to improve Cas9-mediated HDR approximately two-fold in safe harbor AAVS1 locus of human ESCs/iPSCs. Editing was further enhanced with overexpression of Rad51 in combination with VPA treatment [106]. Additional HDAC inhibitors including trichostatin A (TSA) and PCI-24,781 have also been shown to enhance CRISPR/Cas9-mediated gene insertion in porcine fetal fibroblasts; however, this effect was not specific to HDR, as NHEJ repair also increased [107].

Lastly, L755507, a $\beta 3$-adrenergic receptor agonist, was identified in a screen to improve HDR-mediated gene insertion in mouse embryonic stem cells. Unlike the majority of small molecules that target DNA repair, the mechanism of L755507 remains unknown. HDRmediated CRISPR editing of the ACTA2 locus in K562 cells was slightly improved with L755507 [108]. This result was repeated in K562 using a Cas9 RNP with an AAV6 donor targeting the CD45 locus [90]. As with other small molecules discussed above, efficacy in CD34+ HSPCs will ultimately determine potential clinical application.

\subsection{Cas9 Fusion Proteins}

Another strategy to increase HDR utilizes chemical conjugation of small proteins or effector domains to the Cas9 enzyme itself. This allows for direct delivery to the site of the double-stranded break, increasing their local concentration and potency. Conjugation of Cas9 to CtIP has been shown to improve HDR editing in HEK293T cells [109,110]. Importantly, while both studies show significantly increased HDR-mediated gene integration over Cas9 alone, HDR efficiency was highly dependent on the targeted genetic locus and gRNAs. Moreover, the oligomerization domain of CtIP was shown to have variable importance depending on the cell line [110]. These results emphasize the importance of testing this strategy in primary HSPCs.

As with small molecules, Cas9 fusion enzymes have also been used to inhibit the NHEJ pathway. Using a dominant negative mutant of 53BP1 called DN1S conjugated to Cas9, HDR-mediated gene insertion of CD18 cDNA improved from $26 \%$ to $51 \%$ at the AAVS1 target locus in primary B-cells derived from patients with leukocyte adhesion deficiency type 1 (LAD-1). Over $20 \%$ of the positive cells were also shown to have bi-allelic gene integration. Importantly, NHEJ inhibition was local rather than global, an advantage of this strategy over small molecules [111].

In addition to targeting DNA repair pathways, Cas9-fusion with the protein Geminin has also been used to synchronize gene editing with the cell cycle. Geminin is ubiquitylated and degraded during late M-G1 phase by APC, and thus restricts Cas9 activity to the HDR permissive S/G2 phase $[68,112]$. Work by Donald Kohn's group showed that using hGemCas9 enzyme to target the HBB in HSPCs significantly decreased NHEJ, however did not improve rates of HDR. Addition of the CDK1 inhibitor RO increased the HDR/NHEJ ratio four-fold in vitro by further reducing NHEJ; however, toxicity of RO will likely preclude its clinical use.

\section{3. ssODN-Cas9 Conjugates}

A large number of Cas9 conjugated to ssODN donor templates have recently been shown to be successful alternatives to viral delivery of template DNA. Similar to Cas9 fusion proteins, the benefit of this approach is delivery of the donor template directly to the site of the DSB, potentially increasing the frequency and the rate at which SSTR editing 
occurs. Multiple strategies for Cas9-fusion proteins exist, primarily differing in the design of the conjugation method. Examples include an RNA aptamer-streptavidin strategy called S1mplex [113], a Cas9-SNAP fusion protein that covalently links to a modified ssODN [114], a Cas9-HUH endonuclease fusion protein that associates with an unmodified ssODN [115], and a gRNA-donor DNA conjugate (gDonor) [116]. Recently Ling and colleagues developed a modified Cas9 in which a synthetic amino acid is conjugated to a short DNA adaptor to allow its association with an ssODN template. This DNA to DNA adaptor system, rather than protein to ssODN, allows for ease of conjugation. It is also an improvement over biotin-streptavidin methods, as the linker is not cleavable by proteases. Furthermore, non-chemically modified ssODNs can be used. The authors report a 10-fold increase in HDR in HEK293 cells and a three-fold increase in mouse zygotes [117]. While these strategies have yet to be tested in HSPCs for diseases such as sickle cell, where large gene insertions are not required, this may prove to be beneficial.

\section{Strategies to Bypass HDR-Mediated Gene Editing}

While significant progress has been made in recent years to increase frequencies of HDR alleles after gene editing, alternative strategies that rely on end-joining DNA repair pathways, namely NHEJ and alt-NHEJ, have also been proposed to bypass the inefficiencies of HDR-mediated approaches for precise gene editing.

\subsection{Homology-Independent Targeted Insertion (HITI)}

Homology-independent targeted insertion (HITI) uses an NHEJ-based homologyindependent approach in which Cas9 mediates a DSB within both the targeted genomic locus and the complementary sequence of the donor DNA template. The linearized template can then be inserted at the genomic locus by NHEJ repair. Correct insertion of the template in the forward orientation destroys the Cas9 nuclease cut site, while reverse insertion retains the Cas9 sequence, which can be re-cut [118]. This method resulted in gene insertion in about $55 \%$ of transfected primary neurons, with greater than $90 \%$ of insertions resulting in precise editing. In vivo, AAV HITI template delivery in a rat model of retinitis pigmentosa, an inherited disorder causing blindness in humans, partially corrected both pathological disease and visual function [118]. More recently, in vivo HITI delivery using synthetic supramolecular nanoparticles (SMNP) successfully inserted the therapeutic gene Retinoschisis 1 (RS1) into mouse retinal tissue within the Rosa26 locus [119]. Our group showed that HITI can also be used for gene insertion in primary human HSPCs. Using a Cas9 RNP and AAV6 with a GFP-vector targeting exon 1 of the ITGB2 locus, mutated in LAD-1, we could successfully achieve an average of $11 \%$ GFP positivity in HSPCs, persisting in culture up to four weeks post editing. Colony forming unit assays reveal that HITI does not result in lineage skewing, and HITI-edited HSPCs transplanted into immunodeficient NSG mice comprised an average of $21 \%$ of engrafted human CD45+ cells within the bone marrow 18 weeks post-transplantation [120]. These promising results indicate that HITI has the potential to complement HDR strategies currently used for HSPC gene editing.

\subsection{Precise Integration into Target Chromosome (PITCh)}

An alternative approach to gene insertion termed precise integration into target chromosome (PITCh) relies on the alt-NHEJ DNA repair pathway. PITCh vectors have small microhomology sequences to the target locus, which flank the template gene. Similarly to HITI, a CRISPR/Cas9 DSBs is made in both the target gene of interest and exogenous template, which is then integrated at the target site [121]. While showing a clear advantage over HDR in vivo in mouse liver and neurons [122], a direct comparison of PITCh to HITI in primary neurons in vitro revealed a significant benefit of the HITI approach. These differences are likely due in part to in vitro versus in vivo delivery methods as well as gene targets. 


\subsection{Homology-Mediated End Joining (HMEJ)}

A hybrid approach termed homology-mediated end joining (HMEJ) flanks a gene of interest with $800 \mathrm{bp}$ HAs rather than microhomology sequences and, similar to the HITI approach, positions Cas9 target sites outside the homology arms. Thus, the HMEJ strategy can take advantage of both the HDR and end-joining pathways to insert a gene of interest into the genomic cut site [123]. To our knowledge, neither HMEJ nor PITCh have yet been utilized in HSPCs; a direct comparison of homology-independent and dependent methods in HSPCs would be of great interest.

\section{Conclusions}

A burst of scientific advances have led to improved gene editing modalities in recent years. Various challenges remain to fully realize targeted gene therapies of HSPC disorders, including further improving editing efficiencies to levels necessary for overall clinical benefit, understanding innate and adaptive immune responses to editing effector molecules and donor templates, limiting the risks of editing at off-target sites, and addressing the restricted availability of these therapies in underdeveloped nations.

Whereas this manuscript emphasizes the impact of modulating DNA repair and cell cycle pathways to increase percentages of edited HSPCs, alternative strategies have also evolved to circumvent the shortcomings of current protocols. Notably, the recent inception of base editors [8-11] and prime editing approaches [12] that do not depend on cellular DSB repair mechanisms, although limited to alterations of small sequences, may favor highefficiency editing in quiescent HSPCs. Development of safe and effective ex vivo expansion platforms for genetically modified long-term repopulating HSPCs could also provide a clinically valuable strategy to increase cell doses and therapeutic efficacy. However, the development of clinically relevant methodologies for expansion of adult HSPCs remains a challenging goal in clinical hematology. A more refined understanding of the target cell's underlying biology is needed for this approach to gain full therapeutic momentum. In contrast, in disorders such as Fanconi anemia, where rare genetically corrected HSPCs exhibit a powerful in vivo growth advantage after transplantation, ex vivo expansion may not be required, and low-efficiency editing may suffice for therapeutic relevance in these patients [124-126].

Ex vivo genome editing of human HSPCs has entered clinical trials [21], but continued innovations will be necessary to provide new or optimized schemata for diseases requiring high-efficiency precision editing. The prospect of durable clinical benefits in HSPC disorders, however, justifies continued support for this evolving class of medicines.

Author Contributions: Manuscript writing, editing, and reviewing were done by C.T.S.-R. and A.L. All authors have read and agreed to the published version of the manuscript.

Funding: This work was supported by the Intramural Research Program of the National Heart, Lung, and Blood Institute, National Institutes of Health (Z99 HL999999).

Institutional Review Board Statement: Not applicable.

Informed Consent Statement: Not applicable.

Data Availability Statement: Data sharing not applicable.

Conflicts of Interest: The authors declare no conflict of interest.

\section{References}

1. Friedmann, T.; Roblin, R. Gene therapy for human genetic disease? Science 1972, 175, 949-955. [CrossRef] [PubMed]

2. Cavazzana-Calvo, M.; Hacein-Bey, S.; de Saint Basile, G.; Gross, F.; Yvon, E.; Nusbaum, P.; Selz, F.; Hue, C.; Certain, S.; Casanova, J.L.; et al. Gene therapy of human severe combined immunodeficiency (SCID)-X1 disease [see comments]. Science 2000, 288, 669-672. [CrossRef] [PubMed]

3. Hacein-Bey-Abina, S.; Hauer, J.; Lim, A.; Picard, C.; Wang, G.P.; Berry, C.C.; Martinache, C.; Rieux-Laucat, F.; Latour, S.; Belohradsky, B.H.; et al. Efficacy of gene therapy for X-linked severe combined immunodeficiency. N. Engl. J. Med. 2010, 363, 355-364. [CrossRef] 
4. Hacein-Bey-Abina, S.; Le Deist, F.; Carlier, F.; Bouneaud, C.; Hue, C.; De Villartay, J.P.; Thrasher, A.J.; Wulffraat, N.; Sorensen, R.; Dupuis-Girod, S.; et al. Sustained correction of X-linked severe combined immunodeficiency by ex vivo gene therapy. N. Engl. J. Med. 2002, 346, 1185-1193. [CrossRef] [PubMed]

5. Hacein-Bey-Abina, S.; Garrigue, A.; Wang, G.P.; Soulier, J.; Lim, A.; Morillon, E.; Clappier, E.; Caccavelli, L.; Delabesse, E.; Beldjord, K.; et al. Insertional oncogenesis in 4 patients after retrovirus-mediated gene therapy of SCID-X1. J. Clin. Investig. 2008, 118, 3132-3142. [CrossRef] [PubMed]

6. Hacein-Bey-Abina, S.; von Kalle, C.; Schmidt, M.; Le Deist, F.; Wulffraat, N.; McIntyre, E.; Radford, I.; Villeval, J.L.; Fraser, C.C.; Cavazzana-Calvo, M.; et al. A serious adverse event after successful gene therapy for X-linked severe combined immunodeficiency. N. Engl. J. Med. 2003, 348, 255-256. [CrossRef] [PubMed]

7. Hacein-Bey-Abina, S.; Von Kalle, C.; Schmidt, M.; McCormack, M.P.; Wulffraat, N.; Leboulch, P.; Lim, A.; Osborne, C.S.; Pawliuk, R.; Morillon, E.; et al. LMO2-associated clonal T cell proliferation in two patients after gene therapy for SCID-X1. Science 2003, 302, 415-419. [CrossRef]

8. Gaudelli, N.M.; Komor, A.C.; Rees, H.A.; Packer, M.S.; Badran, A.H.; Bryson, D.I.; Liu, D.R. Programmable base editing of A*T to $\mathrm{G}^{*} \mathrm{C}$ in genomic DNA without DNA cleavage. Nature 2017, 551, 464-471. [CrossRef] [PubMed]

9. Komor, A.C.; Kim, Y.B.; Packer, M.S.; Zuris, J.A.; Liu, D.R. Programmable editing of a target base in genomic DNA without double-stranded DNA cleavage. Nature 2016, 533, 420-424. [CrossRef]

10. Rees, H.A.; Liu, D.R. Base editing: Precision chemistry on the genome and transcriptome of living cells. Nat. Rev. Genet. 2018, 19, 770-788. [CrossRef]

11. Yang, B.; Yang, L.; Chen, J. Development and Application of Base Editors. CRISPR J. 2019, 2, 91-104. [CrossRef] [PubMed]

12. Anzalone, A.V.; Randolph, P.B.; Davis, J.R.; Sousa, A.A.; Koblan, L.W.; Levy, J.M.; Chen, P.J.; Wilson, C.; Newby, G.A.; Raguram, A.; et al. Search-and-replace genome editing without double-strand breaks or donor DNA. Nature 2019, 576, 149-157. [CrossRef] [PubMed]

13. Chaikind, B.; Bessen, J.L.; Thompson, D.B.; Hu, J.H.; Liu, D.R. A programmable Cas9-serine recombinase fusion protein that operates on DNA sequences in mammalian cells. Nucleic Acids Res. 2016, 44, 9758-9770. [CrossRef] [PubMed]

14. Chen, S.P.; Wang, H.H. An Engineered Cas-Transposon System for Programmable and Site-Directed DNA Transpositions. CRISPR J. 2019, 2, 376-394. [CrossRef]

15. Klompe, S.E.; Vo, P.L.H.; Halpin-Healy, T.S.; Sternberg, S.H. Transposon-encoded CRISPR-Cas systems direct RNA-guided DNA integration. Nature 2019, 571, 219-225. [CrossRef]

16. Strecker, J.; Ladha, A.; Gardner, Z.; Schmid-Burgk, J.L.; Makarova, K.S.; Koonin, E.V.; Zhang, F. RNA-guided DNA insertion with CRISPR-associated transposases. Science 2019, 365, 48-53. [CrossRef]

17. Anzalone, A.V.; Koblan, L.W.; Liu, D.R. Genome editing with CRISPR-Cas nucleases, base editors, transposases and prime editors. Nat. Biotechnol. 2020, 38, 824-844. [CrossRef]

18. Kim, Y.G.; Cha, J.; Chandrasegaran, S. Hybrid restriction enzymes: Zinc finger fusions to Fok I cleavage domain. Proc. Natl. Acad. Sci. USA 1996, 93, 1156-1160. [CrossRef]

19. Bibikova, M.; Golic, M.; Golic, K.G.; Carroll, D. Targeted chromosomal cleavage and mutagenesis in Drosophila using zinc-finger nucleases. Genetics 2002, 161, 1169-1175.

20. Urnov, F.D.; Miller, J.C.; Lee, Y.L.; Beausejour, C.M.; Rock, J.M.; Augustus, S.; Jamieson, A.C.; Porteus, M.H.; Gregory, P.D.; Holmes, M.C. Highly efficient endogenous human gene correction using designed zinc-finger nucleases. Nature 2005, 435, 646-651. [CrossRef]

21. Porteus, M.H. A New Class of Medicines through DNA Editing. N. Engl. J. Med. 2019, 380, 947-959. [CrossRef] [PubMed]

22. Dunbar, C.E.; High, K.A.; Joung, J.K.; Kohn, D.B.; Ozawa, K.; Sadelain, M. Gene therapy comes of age. Science 2018, 359. [CrossRef] [PubMed]

23. Boch, J.; Bonas, U. Xanthomonas AvrBs3 family-type III effectors: Discovery and function. Annu. Rev. Phytopathol. 2010, 48, 419-436. [CrossRef] [PubMed]

24. Boch, J.; Scholze, H.; Schornack, S.; Landgraf, A.; Hahn, S.; Kay, S.; Lahaye, T.; Nickstadt, A.; Bonas, U. Breaking the code of DNA binding specificity of TAL-type III effectors. Science 2009, 326, 1509-1512. [CrossRef]

25. Bogdanove, A.J.; Voytas, D.F. TAL effectors: Customizable proteins for DNA targeting. Science 2011, 333, 1843-1846. [CrossRef]

26. Saydaminova, K.; Ye, X.; Wang, H.; Richter, M.; Ho, M.; Chen, H.; Xu, N.; Kim, J.S.; Papapetrou, E.; Holmes, M.C.; et al. Efficient genome editing in hematopoietic stem cells with helper-dependent Ad5/35 vectors expressing site-specific endonucleases under microRNA regulation. Mol. Ther. Methods Clin. Dev. 2015, 1, 14057. [CrossRef]

27. DeWitt, M.A.; Magis, W.; Bray, N.L.; Wang, T.; Berman, J.R.; Urbinati, F.; Heo, S.J.; Mitros, T.; Munoz, D.P.; Boffelli, D.; et al. Selection-free genome editing of the sickle mutation in human adult hematopoietic stem/progenitor cells. Sci. Transl. Med. 2016, 8, 360ra134. [CrossRef]

28. Jinek, M.; Chylinski, K.; Fonfara, I.; Hauer, M.; Doudna, J.A.; Charpentier, E. A programmable dual-RNA-guided DNA endonuclease in adaptive bacterial immunity. Science 2012, 337, 816-821. [CrossRef]

29. Barrangou, R.; Fremaux, C.; Deveau, H.; Richards, M.; Boyaval, P.; Moineau, S.; Romero, D.A.; Horvath, P. CRISPR provides acquired resistance against viruses in prokaryotes. Science 2007, 315, 1709-1712. [CrossRef] 
30. Hendel, A.; Bak, R.O.; Clark, J.T.; Kennedy, A.B.; Ryan, D.E.; Roy, S.; Steinfeld, I.; Lunstad, B.D.; Kaiser, R.J.; Wilkens, A.B.; et al. Chemically modified guide RNAs enhance CRISPR-Cas genome editing in human primary cells. Nat. Biotechnol. 2015, 33, 985-989. [CrossRef]

31. Chen, J.S.; Dagdas, Y.S.; Kleinstiver, B.P.; Welch, M.M.; Sousa, A.A.; Harrington, L.B.; Sternberg, S.H.; Joung, J.K.; Yildiz, A.; Doudna, J.A. Enhanced proofreading governs CRISPR-Cas9 targeting accuracy. Nature 2017, 550, 407-410. [CrossRef] [PubMed]

32. Muller, M.; Lee, C.M.; Gasiunas, G.; Davis, T.H.; Cradick, T.J.; Siksnys, V.; Bao, G.; Cathomen, T.; Mussolino, C. Streptococcus thermophilus CRISPR-Cas9 Systems Enable Specific Editing of the Human Genome. Mol. Ther. 2016, 24, 636-644. [CrossRef] [PubMed]

33. Acharya, S.; Mishra, A.; Paul, D.; Ansari, A.H.; Azhar, M.; Kumar, M.; Rauthan, R.; Sharma, N.; Aich, M.; Sinha, D.; et al. Francisella novicida Cas9 interrogates genomic DNA with very high specificity and can be used for mammalian genome editing. Proc. Natl. Acad. Sci. USA 2019, 116, 20959-20968. [CrossRef] [PubMed]

34. Strecker, J.; Jones, S.; Koopal, B.; Schmid-Burgk, J.; Zetsche, B.; Gao, L.; Makarova, K.S.; Koonin, E.V.; Zhang, F. Engineering of CRISPR-Cas12b for human genome editing. Nat. Commun. 2019, 10, 212. [CrossRef] [PubMed]

35. Vakulskas, C.A.; Dever, D.P.; Rettig, G.R.; Turk, R.; Jacobi, A.M.; Collingwood, M.A.; Bode, N.M.; McNeill, M.S.; Yan, S.; Camarena, J.; et al. A high-fidelity Cas9 mutant delivered as a ribonucleoprotein complex enables efficient gene editing in human hematopoietic stem and progenitor cells. Nat. Med. 2018, 24, 1216-1224. [CrossRef] [PubMed]

36. Ran, F.A.; Cong, L.; Yan, W.X.; Scott, D.A.; Gootenberg, J.S.; Kriz, A.J.; Zetsche, B.; Shalem, O.; Wu, X.; Makarova, K.S.; et al. In vivo genome editing using Staphylococcus aureus Cas9. Nature 2015, 520, 186-191. [CrossRef]

37. Luan, B.; Xu, G.; Feng, M.; Cong, L.; Zhou, R. Combined Computational-Experimental Approach to Explore the Molecular Mechanism of SaCas9 with a Broadened DNA Targeting Range. J. Am. Chem. Soc. 2019, 141, 6545-6552. [CrossRef]

38. Kim, E.; Koo, T.; Park, S.W.; Kim, D.; Kim, K.; Cho, H.Y.; Song, D.W.; Lee, K.J.; Jung, M.H.; Kim, S.; et al. In vivo genome editing with a small Cas9 orthologue derived from Campylobacter jejuni. Nat. Commun. 2017, 8, 14500. [CrossRef]

39. Edraki, A.; Mir, A.; Ibraheim, R.; Gainetdinov, I.; Yoon, Y.; Song, C.Q.; Cao, Y.; Gallant, J.; Xue, W.; Rivera-Perez, J.A.; et al. A Compact, High-Accuracy Cas9 with a Dinucleotide PAM for In Vivo Genome Editing. Mol. Cell 2019, 73, 714-726.e4. [CrossRef]

40. Liu, J.J.; Orlova, N.; Oakes, B.L.; Ma, E.; Spinner, H.B.; Baney, K.L.M.; Chuck, J.; Tan, D.; Knott, G.J.; Harrington, L.B.; et al. CasX enzymes comprise a distinct family of RNA-guided genome editors. Nature 2019, 566, 218-223. [CrossRef]

41. Kleinstiver, B.P.; Prew, M.S.; Tsai, S.Q.; Topkar, V.V.; Nguyen, N.T.; Zheng, Z.; Gonzales, A.P.; Li, Z.; Peterson, R.T.; Yeh, J.R.; et al. Engineered CRISPR-Cas9 nucleases with altered PAM specificities. Nature 2015, 523, 481-485. [CrossRef] [PubMed]

42. Hou, Z.; Zhang, Y.; Propson, N.E.; Howden, S.E.; Chu, L.F.; Sontheimer, E.J.; Thomson, J.A. Efficient genome engineering in human pluripotent stem cells using Cas9 from Neisseria meningitidis. Proc. Natl. Acad. Sci. USA 2013, 110, 15644-15649. [CrossRef] [PubMed]

43. Walton, R.T.; Christie, K.A.; Whittaker, M.N.; Kleinstiver, B.P. Unconstrained genome targeting with near-PAMless engineered CRISPR-Cas9 variants. Science 2020, 368, 290-296. [CrossRef] [PubMed]

44. Chatterjee, P.; Jakimo, N.; Lee, J.; Amrani, N.; Rodriguez, T.; Koseki, S.R.T.; Tysinger, E.; Qing, R.; Hao, S.; Sontheimer, E.J.; et al. An engineered ScCas9 with broad PAM range and high specificity and activity. Nat. Biotechnol. 2020, 38, 1154-1158. [CrossRef]

45. Legut, M.; Daniloski, Z.; Xue, X.; McKenzie, D.; Guo, X.; Wessels, H.H.; Sanjana, N.E. High-Throughput Screens of PAM-Flexible Cas9 Variants for Gene Knockout and Transcriptional Modulation. Cell Rep. 2020, 30, 2859-2868.e5. [CrossRef] [PubMed]

46. Yeh, C.D.; Richardson, C.D.; Corn, J.E. Advances in genome editing through control of DNA repair pathways. Nat. Cell Biol. 2019, 21, 1468-1478. [CrossRef]

47. Heyer, W.D.; Ehmsen, K.T.; Liu, J. Regulation of homologous recombination in eukaryotes. Annu. Rev. Genet. 2010, 44, 113-139. [CrossRef]

48. Mohrin, M.; Bourke, E.; Alexander, D.; Warr, M.R.; Barry-Holson, K.; Le Beau, M.M.; Morrison, C.G.; Passegue, E. Hematopoietic stem cell quiescence promotes error-prone DNA repair and mutagenesis. Cell Stem Cell 2010, 7, 174-185. [CrossRef]

49. Nijnik, A.; Woodbine, L.; Marchetti, C.; Dawson, S.; Lambe, T.; Liu, C.; Rodrigues, N.P.; Crockford, T.L.; Cabuy, E.; Vindigni, A.; et al. DNA repair is limiting for haematopoietic stem cells during ageing. Nature 2007, 447, 686-690. [CrossRef]

50. Rossi, D.J.; Bryder, D.; Seita, J.; Nussenzweig, A.; Hoeijmakers, J.; Weissman, I.L. Deficiencies in DNA damage repair limit the function of haematopoietic stem cells with age. Nature 2007, 447, 725-729. [CrossRef]

51. Mimitou, E.P.; Symington, L.S. Ku prevents Exo1 and Sgs1-dependent resection of DNA ends in the absence of a functional MRX complex or Sae2. EMBO J. 2010, 29, 3358-3369. [CrossRef] [PubMed]

52. Ira, G.; Pellicioli, A.; Balijja, A.; Wang, X.; Fiorani, S.; Carotenuto, W.; Liberi, G.; Bressan, D.; Wan, L.; Hollingsworth, N.M.; et al. DNA end resection, homologous recombination and DNA damage checkpoint activation require CDK1. Nature 2004, 431, 1011-1017. [CrossRef] [PubMed]

53. Peterson, S.E.; Li, Y.; Chait, B.T.; Gottesman, M.E.; Baer, R.; Gautier, J. Cdk1 uncouples CtIP-dependent resection and Rad51 filament formation during M-phase double-strand break repair. J. Cell Biol. 2011, 194, 705-720. [CrossRef] [PubMed]

54. Yun, M.H.; Hiom, K. CtIP-BRCA1 modulates the choice of DNA double-strand-break repair pathway throughout the cell cycle. Nature 2009, 459, 460-463. [CrossRef] [PubMed] 
55. Sfeir, A.; Symington, L.S. Microhomology-Mediated End Joining: A Back-up Survival Mechanism or Dedicated Pathway? Trends Biochem. Sci. 2015, 40, 701-714. [CrossRef] [PubMed]

56. Truong, L.N.; Li, Y.; Shi, L.Z.; Hwang, P.Y.; He, J.; Wang, H.; Razavian, N.; Berns, M.W.; Wu, X. Microhomology-mediated End Joining and Homologous Recombination share the initial end resection step to repair DNA double-strand breaks in mammalian cells. Proc. Natl. Acad. Sci. USA 2013, 110, 7720-7725. [CrossRef] [PubMed]

57. Yan, C.T.; Boboila, C.; Souza, E.K.; Franco, S.; Hickernell, T.R.; Murphy, M.; Gumaste, S.; Geyer, M.; Zarrin, A.A.; Manis, J.P.; et al. IgH class switching and translocations use a robust non-classical end-joining pathway. Nature 2007, 449, 478-482. [CrossRef]

58. Sartori, A.A.; Lukas, C.; Coates, J.; Mistrik, M.; Fu, S.; Bartek, J.; Baer, R.; Lukas, J.; Jackson, S.P. Human CtIP promotes DNA end resection. Nature 2007, 450, 509-514. [CrossRef]

59. Nimonkar, A.V.; Genschel, J.; Kinoshita, E.; Polaczek, P.; Campbell, J.L.; Wyman, C.; Modrich, P.; Kowalczykowski, S.C. BLMDNA2-RPA-MRN and EXO1-BLM-RPA-MRN constitute two DNA end resection machineries for human DNA break repair. Genes Dev. 2011, 25, 350-362. [CrossRef]

60. Bhargava, R.; Onyango, D.O.; Stark, J.M. Regulation of Single-Strand Annealing and its Role in Genome Maintenance. Trends Genet. 2016, 32, 566-575. [CrossRef]

61. Jasin, M.; de Villiers, J.; Weber, F.; Schaffner, W. High frequency of homologous recombination in mammalian cells between endogenous and introduced SV40 genomes. Cell 1985, 43, 695-703. [CrossRef]

62. Jensen, R.B.; Carreira, A.; Kowalczykowski, S.C. Purified human BRCA2 stimulates RAD51-mediated recombination. Nature 2010, 467, 678-683. [CrossRef] [PubMed]

63. Liu, J.; Doty, T.; Gibson, B.; Heyer, W.D. Human BRCA2 protein promotes RAD51 filament formation on RPA-covered singlestranded DNA. Nat. Struct. Mol. Biol. 2010, 17, 1260-1262. [CrossRef] [PubMed]

64. Thorslund, T.; Mcllwraith, M.J.; Compton, S.A.; Lekomtsev, S.; Petronczki, M.; Griffith, J.D.; West, S.C. The breast cancer tumor suppressor BRCA2 promotes the specific targeting of RAD51 to single-stranded DNA. Nat. Struct. Mol. Biol. 2010, 17, 1263-1265. [CrossRef] [PubMed]

65. Kadyk, L.C.; Hartwell, L.H. Sister chromatids are preferred over homologs as substrates for recombinational repair in Saccharomyces cerevisiae. Genetics 1992, 132, 387-402. [CrossRef]

66. Branzei, D.; Foiani, M. Regulation of DNA repair throughout the cell cycle. Nat. Rev. Mol. Cell Biol. 2008, 9, 297-308. [CrossRef]

67. Richardson, C.D.; Kazane, K.R.; Feng, S.J.; Zelin, E.; Bray, N.L.; Schafer, A.J.; Floor, S.N.; Corn, J.E. CRISPR-Cas9 genome editing in human cells occurs via the Fanconi anemia pathway. Nat. Genet. 2018, 50, 1132-1139. [CrossRef]

68. Lomova, A.; Clark, D.N.; Campo-Fernandez, B.; Flores-Bjurstrom, C.; Kaufman, M.L.; Fitz-Gibbon, S.; Wang, X.; Miyahira, E.Y.; Brown, D.; DeWitt, M.A.; et al. Improving Gene Editing Outcomes in Human Hematopoietic Stem and Progenitor Cells by Temporal Control of DNA Repair. Stem Cells 2019, 37, 284-294. [CrossRef]

69. Ates, I.; Rathbone, T.; Stuart, C.; Bridges, P.H.; Cottle, R.N. Delivery Approaches for Therapeutic Genome Editing and Challenges. Genes 2020, 11, 1113. [CrossRef]

70. Smith, R.H.; Chen, Y.C.; Seifuddin, F.; Hupalo, D.; Alba, C.; Reger, R.; Tian, X.; Araki, D.; Dalgard, C.L.; Childs, R.W.; et al. Genome-Wide Analysis of Off-Target CRISPR/Cas9 Activity in Single-Cell-Derived Human Hematopoietic Stem and Progenitor Cell Clones. Genes 2020, 11, 1501. [CrossRef]

71. De Ravin, S.S.; Li, L.; Wu, X.; Choi, U.; Allen, C.; Koontz, S.; Lee, J.; Theobald-Whiting, N.; Chu, J.; Garofalo, M.; et al. CRISPR-Cas9 gene repair of hematopoietic stem cells from patients with X-linked chronic granulomatous disease. Sci. Transl. Med. 2017, 9. [CrossRef] [PubMed]

72. Riesenberg, S.; Chintalapati, M.; Macak, D.; Kanis, P.; Maricic, T.; Paabo, S. Simultaneous precise editing of multiple genes in human cells. Nucleic Acids Res. 2019, 47, e116. [CrossRef] [PubMed]

73. Wienert, B.; Nguyen, D.N.; Guenther, A.; Feng, S.J.; Locke, M.N.; Wyman, S.K.; Shin, J.; Kazane, K.R.; Gregory, G.L.; Carter, M.A.M.; et al. Timed inhibition of CDC7 increases CRISPR-Cas9 mediated templated repair. Nat. Commun. 2020, 11, 2109. [CrossRef] [PubMed]

74. Hoban, M.D.; Cost, G.J.; Mendel, M.C.; Romero, Z.; Kaufman, M.L.; Joglekar, A.V.; Ho, M.; Lumaquin, D.; Gray, D.; Lill, G.R.; et al. Correction of the sickle cell disease mutation in human hematopoietic stem/progenitor cells. Blood 2015, 125, 2597-2604. [CrossRef] [PubMed]

75. Hoban, M.D.; Lumaquin, D.; Kuo, C.Y.; Romero, Z.; Long, J.; Ho, M.; Young, C.S.; Mojadidi, M.; Fitz-Gibbon, S.; Cooper, A.R.; et al. CRISPR/Cas9-Mediated Correction of the Sickle Mutation in Human CD34+ cells. Mol. Ther. 2016, 24, 1561-1569. [CrossRef]

76. Genovese, P.; Schiroli, G.; Escobar, G.; Tomaso, T.D.; Firrito, C.; Calabria, A.; Moi, D.; Mazzieri, R.; Bonini, C.; Holmes, M.C.; et al. Targeted genome editing in human repopulating haematopoietic stem cells. Nature 2014, 510, 235-240. [CrossRef]

77. Wang, J.; Exline, C.M.; DeClercq, J.J.; Llewellyn, G.N.; Hayward, S.B.; Li, P.W.; Shivak, D.A.; Surosky, R.T.; Gregory, P.D.; Holmes, M.C.; et al. Homology-driven genome editing in hematopoietic stem and progenitor cells using ZFN mRNA and AAV6 donors. Nat. Biotechnol. 2015, 33, 1256-1263. [CrossRef]

78. Hanlon, K.S.; Kleinstiver, B.P.; Garcia, S.P.; Zaborowski, M.P.; Volak, A.; Spirig, S.E.; Muller, A.; Sousa, A.A.; Tsai, S.Q.; Bengtsson, N.E.; et al. High levels of AAV vector integration into CRISPR-induced DNA breaks. Nat. Commun. 2019, 10, 4439. [CrossRef] 
79. Dever, D.P.; Bak, R.O.; Reinisch, A.; Camarena, J.; Washington, G.; Nicolas, C.E.; Pavel-Dinu, M.; Saxena, N.; Wilkens, A.B.; Mantri, S.; et al. CRISPR/Cas9 beta-globin gene targeting in human haematopoietic stem cells. Nature 2016, 539, 384-389. [CrossRef]

80. Schiroli, G.; Ferrari, S.; Conway, A.; Jacob, A.; Capo, V.; Albano, L.; Plati, T.; Castiello, M.C.; Sanvito, F.; Gennery, A.R.; et al. Preclinical modeling highlights the therapeutic potential of hematopoietic stem cell gene editing for correction of SCID-X1. Sci. Transl. Med. 2017, 9. [CrossRef]

81. Pavel-Dinu, M.; Wiebking, V.; Dejene, B.T.; Srifa, W.; Mantri, S.; Nicolas, C.E.; Lee, C.; Bao, G.; Kildebeck, E.J.; Punjya, N.; et al. Gene correction for SCID-X1 in long-term hematopoietic stem cells. Nat. Commun. 2019, 10, 5624. [CrossRef] [PubMed]

82. De Ravin, S.S.; Reik, A.; Liu, P.-Q.; Li, L.; Wu, X.; Su, L.; Raley, C.; Theobald, N.; Choi, U.; Song, A.H.; et al. Targeted gene addition in human CD34+ hematopoietic cells for correction of X-linked chronic granulomatous disease. Nat. Biotech. 2016, 34, 424-429. [CrossRef] [PubMed]

83. Kuo, C.Y.; Long, J.D.; Campo-Fernandez, B.; Oliveira, S.d.; Cooper, A.R.; Romero, Z.; Hoban, M.D.; Joglekar, A.V.; Lill, G.R.; Kaufman, M.L.; et al. Site-Specific Gene Editing of Human Hematopoietic Stem Cells for X-Linked Hyper-IgM Syndrome. Cell Rep. 2018, 23, 2606-2616. [CrossRef] [PubMed]

84. Tran, N.T.; Graf, R.; Wulf-Goldenberg, A.; Stecklum, M.; Strauss, G.; Kuhn, R.; Kocks, C.; Rajewsky, K.; Chu, V.T. CRISPR-Cas9Mediated ELANE Mutation Correction in Hematopoietic Stem and Progenitor Cells to Treat Severe Congenital Neutropenia. Mol. Ther. 2020, 28, 2621-2634. [CrossRef] [PubMed]

85. Rai, R.; Romito, M.; Rivers, E.; Turchiano, G.; Blattner, G.; Vetharoy, W.; Ladon, D.; Andrieux, G.; Zhang, F.; Zinicola, M.; et al. Targeted gene correction of human hematopoietic stem cells for the treatment of Wiskott-Aldrich Syndrome. Nat. Commun. 2020, 11, 4034. [CrossRef]

86. Gomez-Ospina, N.; Scharenberg, S.G.; Mostrel, N.; Bak, R.O.; Mantri, S.; Quadros, R.M.; Gurumurthy, C.B.; Lee, C.; Bao, G.; Suarez, C.J.; et al. Human genome-edited hematopoietic stem cells phenotypically correct Mucopolysaccharidosis type I. Nat. Commun. 2019, 10, 4045. [CrossRef]

87. Pavani, G.; Laurent, M.; Fabiano, A.; Cantelli, E.; Sakkal, A.; Corre, G.; Lenting, P.J.; Concordet, J.P.; Toueille, M.; Miccio, A.; et al. Ex vivo editing of human hematopoietic stem cells for erythroid expression of therapeutic proteins. Nat. Commun. 2020, 11, 3778. [CrossRef]

88. Hubbard, N.; Hagin, D.; Sommer, K.; Song, Y.; Khan, I.; Clough, C.; Ochs, H.D.; Rawlings, D.J.; Scharenberg, A.M.; Torgerson, T.R. Targeted gene editing restores regulated CD40L function in X-linked hyper-IgM syndrome. Blood 2016, 127, 2513-2522. [CrossRef]

89. Gutierrez-Guerrero, A.; Sanchez-Hernandez, S.; Galvani, G.; Pinedo-Gomez, J.; Martin-Guerra, R.; Sanchez-Gilabert, A.; Aguilar-González, A.; Cobo, M.; Gregory, P.; Holmes, M.; et al. Comparison of Zinc Finger Nucleases versus CRISPR-Specific Nucleases for Genome Editing of the Wiskott-Aldrich Syndrome Locus. Hum. Gene Ther. 2018, 29, 366-380. [CrossRef]

90. Jayavaradhan, R.; Pillis, D.M.; Malik, P. A Versatile Tool for the Quantification of CRISPR/Cas9-Induced Genome Editing Events in Human Hematopoietic Cell Lines and Hematopoietic Stem/Progenitor Cells. J. Mol. Biol. 2019, 431, 102-110. [CrossRef]

91. Riesenberg, S.; Maricic, T. Targeting repair pathways with small molecules increases precise genome editing in pluripotent stem cells. Nat. Commun. 2018, 9, 2164. [CrossRef] [PubMed]

92. Jayathilaka, K.; Sheridan, S.D.; Bold, T.D.; Bochenska, K.; Logan, H.L.; Weichselbaum, R.R.; Bishop, D.K.; Connell, P.P. A chemical compound that stimulates the human homologous recombination protein RAD51. Proc. Natl. Acad. Sci. USA 2008, 105, 15848-15853. [CrossRef] [PubMed]

93. Pinder, J.; Salsman, J.; Dellaire, G. Nuclear domain 'knock-in' screen for the evaluation and identification of small molecule enhancers of CRISPR-based genome editing. Nucleic Acids Res. 2015, 43, 9379-9392. [CrossRef] [PubMed]

94. Jeon, I.S.; Shin, J.C.; Kim, S.R.; Park, K.S.; Yoo, H.J.; Lee, K.Y.; Lee, H.K.; Choi, J.K. Role of RS-1 derivatives in homology-directed repair at the human genome ATG5 locus. Arch. Pharm. Res. 2020. [CrossRef] [PubMed]

95. Shin, J.J.; Schroder, M.S.; Caiado, F.; Wyman, S.K.; Bray, N.L.; Bordi, M.; Dewitt, M.A.; Vu, J.T.; Kim, W.T.; Hockemeyer, D.; et al. Controlled Cycling and Quiescence Enables Efficient HDR in Engraftment-Enriched Adult Hematopoietic Stem and Progenitor Cells. Cell Rep. 2020, 32, 108093. [CrossRef] [PubMed]

96. Heffner, G.C.; Bonner, M.; Christiansen, L.; Pierciey, F.J; Campbell, D.; Smurnyy, Y.; Zhang, W.; Hamel, A.; Shaw, S.; Lewis, G.; et al. Prostaglandin E2 Increases Lentiviral Vector Transduction Efficiency of Adult Human Hematopoietic Stem and Progenitor Cells. Mol. Ther. 2018, 26, 320-328. [CrossRef] [PubMed]

97. Boitano, A.E.; Wang, J.; Romeo, R.; Bouchez, L.C.; Parker, A.E.; Sutton, S.E.; Walker, J.R.; Flaveny, C.A.; Perdew, G.H.; Denison, M.S.; et al. Aryl hydrocarbon receptor antagonists promote the expansion of human hematopoietic stem cells. Science 2010, 329, 1345-1348. [CrossRef]

98. Fares, I.; Chagraoui, J.; Gareau, Y.; Gingras, S.; Ruel, R.; Mayotte, N.; Csaszar, E.; Knapp, D.J.; Miller, P.; Ngom, M.; et al. Cord blood expansion. Pyrimidoindole derivatives are agonists of human hematopoietic stem cell self-renewal. Science 2014, 345, 1509-1512. [CrossRef]

99. Bak, R.O.; Dever, D.P.; Porteus, M.H. CRISPR/Cas9 genome editing in human hematopoietic stem cells. Nat. Protoc. 2018, 13, 358-376. [CrossRef] 
100. Charlesworth, C.T.; Camarena, J.; Cromer, M.K.; Vaidyanathan, S.; Bak, R.O.; Carte, J.M.; Potter, J.; Dever, D.P.; Porteus, M.H. Priming Human Repopulating Hematopoietic Stem and Progenitor Cells for Cas9/sgRNA Gene Targeting. Mol. Ther. Nucleic Acids 2018, 12, 89-104. [CrossRef]

101. Glimm, H.; Oh, I.H.; Eaves, C.J. Human hematopoietic stem cells stimulated to proliferate in vitro lose engraftment potential during their $\mathrm{S} / \mathrm{G}(2) / \mathrm{M}$ transit and do not reenter $\mathrm{G}(0)$. Blood 2000, 96, 4185-4193. [CrossRef] [PubMed]

102. Huang, J.; Nguyen-McCarty, M.; Hexner, E.O.; Danet-Desnoyers, G.; Klein, P.S. Maintenance of hematopoietic stem cells through regulation of Wnt and mTOR pathways. Nat. Med. 2012, 18, 1778-1785. [CrossRef] [PubMed]

103. Lin, S.; Staahl, B.T.; Alla, R.K.; Doudna, J.A. Enhanced homology-directed human genome engineering by controlled timing of CRISPR/Cas9 delivery. eLife 2014, 3, e04766. [CrossRef] [PubMed]

104. Yang, D.; Scavuzzo, M.A.; Chmielowiec, J.; Sharp, R.; Bajic, A.; Borowiak, M. Enrichment of G2/M cell cycle phase in human pluripotent stem cells enhances HDR-mediated gene repair with customizable endonucleases. Sci. Rep. 2016, 6, 21264. [CrossRef] [PubMed]

105. Brown, A.; Pospiech, J.; Eiwen, K.; Baker, D.J.; Moehrle, B.; Sakk, V.; Nattamai, K.; Vogel, M.; Grigoryan, A.; Geiger, H. The Spindle Assembly Checkpoint Is Required for Hematopoietic Progenitor Cell Engraftment. Stem Cell Reports 2017, 9, 1359-1368. [CrossRef]

106. Takayama, K.; Igai, K.; Hagihara, Y.; Hashimoto, R.; Hanawa, M.; Sakuma, T.; Tachibana, M.; Sakurai, F.; Yamamoto, T.; Mizuguchi, H. Highly efficient biallelic genome editing of human ES/iPS cells using a CRISPR/Cas9 or TALEN system. Nucleic Acids Res. 2017, 45, 5198-5207. [CrossRef]

107. Li, G.; Zhang, X.; Wang, H.; Liu, D.; Li, Z.; Wu, Z.; Yang, H. Increasing CRISPR/Cas9-mediated homology-directed DNA repair by histone deacetylase inhibitors. Int. J. Biochem. Cell Biol. 2020, 105790. [CrossRef]

108. Yu, C.; Liu, Y.; Ma, T.; Liu, K.; Xu, S.; Zhang, Y.; Liu, H.; La Russa, M.; Xie, M.; Ding, S.; et al. Small molecules enhance CRISPR genome editing in pluripotent stem cells. Cell Stem Cell 2015, 16, 142-147. [CrossRef]

109. Tran, N.T.; Bashir, S.; Li, X.; Rossius, J.; Chu, V.T.; Rajewsky, K.; Kühn, R. Enhancement of Precise Gene Editing by the Association of Cas9 With Homologous Recombination Factors. Front. Genet. 2019, 10, 365. [CrossRef]

110. Charpentier, M.; Khedher, A.H.Y.; Menoret, S.; Brion, A.; Lamribet, K.; Dardillac, E.; Boix, C.; Perrouault, L.; Tesson, L.; Geny, S.; et al. CtIP fusion to Cas9 enhances transgene integration by homology-dependent repair. Nat. Commun. 2018, 9, 1133. [CrossRef]

111. Jayavaradhan, R.; Pillis, D.M.; Goodman, M.; Zhang, F.; Zhang, Y.; Andreassen, P.R.; Malik, P. CRISPR-Cas9 fusion to dominant-negative 53BP1 enhances HDR and inhibits NHEJ specifically at Cas9 target sites. Nat. Commu.n 2019, 10, 2866. [CrossRef] [PubMed]

112. Gutschner, T.; Haemmerle, M.; Genovese, G.; Draetta, G.F.; Chin, L. Post-translational Regulation of Cas9 during G1 Enhances Homology-Directed Repair. Cell Rep. 2016, 14, 1555-1566. [CrossRef] [PubMed]

113. Carlson-Stevermer, J.; Abdeen, A.A.; Kohlenberg, L.; Goedland, M.; Molugu, K.; Lou, M.; Saha, K. Assembly of CRISPR ribonucleoproteins with biotinylated oligonucleotides via an RNA aptamer for precise gene editing. Nat. Commun. 2017, 8, 1711. [CrossRef] [PubMed]

114. Savic, N.; Ringnalda, F.C.; Lindsay, H.; Berk, C.; Bargsten, K.; Li, Y.; Neri, D.; Robinson, M.D.; Ciaudo, C.; Hall, J.; et al. Covalent linkage of the DNA repair template to the CRISPR-Cas9 nuclease enhances homology-directed repair. eLife $2018,7$. [CrossRef] [PubMed]

115. Aird, E.J.; Lovendahl, K.N.; St Martin, A.; Harris, R.S.; Gordon, W.R. Increasing Cas9-mediated homology-directed repair efficiency through covalent tethering of DNA repair template. Commun. Biol. 2018, 1, 54. [CrossRef]

116. Lee, K.; Mackley, V.A.; Rao, A.; Chong, A.T.; Dewitt, M.A.; Corn, J.E.; Murthy, N. Synthetically modified guide RNA and donor DNA are a versatile platform for CRISPR-Cas9 engineering. eLife 2017, 6. [CrossRef]

117. Ling, X.; Xie, B.; Gao, X.; Chang, L.; Zheng, W.; Chen, H.; Huang, Y.; Tan, L.; Li, M.; Liu, T. Improving the efficiency of precise genome editing with site-specific Cas9-oligonucleotide conjugates. Sci. Adv. 2020, 6, eaaz0051. [CrossRef]

118. Suzuki, K.; Tsunekawa, Y.; Hernandez-Benitez, R.; Wu, J.; Zhu, J.; Kim, E.J.; Hatanaka, F.; Yamamoto, M.; Araoka, T.; Li, Z.; et al. In vivo genome editing via CRISPR/Cas9 mediated homology-independent targeted integration. Nature 2016, 540, 144-149. [CrossRef]

119. Chou, S.J.; Yang, P.; Ban, Q.; Yang, Y.P.; Wang, M.L.; Chien, C.S.; Chen, S.J.; Sun, N.; Zhu, Y.; Liu, H.; et al. Dual Supramolecular Nanoparticle Vectors Enable CRISPR/Cas9-Mediated Knockin of Retinoschisin 1 Gene-A Potential Nonviral Therapeutic Solution for X-Linked Juvenile Retinoschisis. Adv. Sci. (Weinh) 2020, 7, 1903432. [CrossRef]

120. Bloomer, H.; Smith, R.H.; Hakami, W.; Larochelle, A. Genome Editing in Human Hematopoietic Stem and Progenitor Cells via CRISPR/Cas9-Mediated Homology-Independent Targeted Integration. Mol. Ther. 2020. [CrossRef]

121. Nakade, S.; Tsubota, T.; Sakane, Y.; Kume, S.; Sakamoto, N.; Obara, M.; Daimon, T.; Sezutsu, H.; Yamamoto, T.; Sakuma, T.; et al. Microhomology-mediated end-joining-dependent integration of donor DNA in cells and animals using TALENs and CRISPR/Cas9. Nat. Commun. 2014, 5, 5560. [CrossRef] [PubMed]

122. Yao, X.; Wang, X.; Liu, J.; Hu, X.; Shi, L.; Shen, X.; Ying, W.; Sun, X.; Wang, X.; Huang, P.; et al. CRISPR/Cas9-Mediated Precise Targeted Integration In Vivo Using a Double Cut Donor with Short Homology Arms. EBioMedicine 2017, $20,19-26$. [CrossRef] [PubMed]

123. Yao, X.; Wang, X.; Hu, X.; Liu, Z.; Liu, J.; Zhou, H.; Shen, X.; Wei, Y.; Huang, Z.; Ying, W.; et al. Homology-mediated end joining-based targeted integration using CRISPR/Cas9. Cell Res. 2017, 27, 801-814. [CrossRef] [PubMed] 
124. Roman-Rodriguez, F.J.; Ugalde, L.; Alvarez, L.; Diez, B.; Ramirez, M.J.; Risueno, C.; Corton, M.; Bogliolo, M.; Bernal, S.; March, F; et al. NHEJ-Mediated Repair of CRISPR-Cas9-Induced DNA Breaks Efficiently Corrects Mutations in HSPCs from Patients with Fanconi Anemia. Cell Stem Cell 2019, 25, 607-621.e7. [CrossRef] [PubMed]

125. Rio, P.; Navarro, S.; Wang, W.; Sanchez-Dominguez, R.; Pujol, R.M.; Segovia, J.C.; Bogliolo, M.; Merino, E.; Wu, N.; Salgado, R.; et al. Successful engraftment of gene-corrected hematopoietic stem cells in non-conditioned patients with Fanconi anemia. Nat. Med. 2019, 25, 1396-1401. [CrossRef]

126. Rio, P.; Navarro, S.; Guenechea, G.; Sanchez-Dominguez, R.; Lamana, M.L.; Yanez, R.; Casado, J.A.; Mehta, P.A.; Pujol, M.R.; Surralles, J.; et al. Engraftment and in vivo proliferation advantage of gene-corrected mobilized CD34(+) cells from Fanconi anemia patients. Blood 2017, 130, 1535-1542. [CrossRef] 